\title{
La relevancia de los llamados conocimientos especiales en la determinación de la violación al deber objetivo de cuidado
}

Andrés Felipe Díaz Arana*

\section{Resumen}

En este escrito, se pretende reseñar el estado actual de la discusión en torno a la ubicación sistemática del estudio de los conocimientos especiales en la teoría material del delito, los límites a la exigencia de activarlos para tales o cuales casos, y las pautas a partir de las cuales han de ser diferenciados de los conocimientos ordinarios o conocimientos comunes. Este desarrollo tiene como fin proponer una definición general de especialidad, que permita determinar con claridad suficiente los criterios que han de emplearse a la hora de determinar cuáles conocimientos son relevantes en la determinación del deber objetivo de cuidado y cuáles no.

\section{Palabras Clave}

Acción, conocimientos especiales, deber objetivo de cuidado, dolo, imprudencia, teoría del delito, omisión.

\section{Introducción, planteamiento del problema y metodología a seguir}

En el curso de Derecho penal, Parte general, al abordar las distintas escuelas de la teoría material del delito el profesor explicaba que, como regla general, ellas suponían distintos caminos para llegar a un mismo resultado en la atribución de responsabilidad. Se refería con ello a que, bien sea desde una perspectiva causalista, finalista o normativista, el resultado -en cuanto a responsabilidad penal o no- tendía a ser el mismo. Rara vez, los postulados de una escuela

${ }^{*}$ Abogado y filósofo de la Universidad de los Andes. 
del delito conllevan a responsabilidad penal o impunidad los de la otra, en un mismo y único caso. Ante este panorama, la importancia del estudio de las escuelas del delito radica, pues, en que estas ofrecen una amalgama de fundamentos iusfilosóficos a través de los cuales puede explicarse la vinculación o no, de la conducta con las formas de responsabilidad penal. Sin embargo, el caso que ocupa el presente estudio, constituye una excepción a dicha regla.

A decir verdad, la teoría general del Derecho penal no se caracteriza por discurrir en un terreno doctrinario pacífico. Por el contrario, en casi todos los puntos de vista importantes se encuentra un sector disidente con relativa fuerza, cuyos planteamientos tienen vocación suficiente para cuestionar seriamente los postulados de la hegemonía mayoritaria. No son muchos los aspectos de la teoría material del delito en los cuales puede hablarse de consenso y en ninguno puede afirmarse la uniformidad. Nudos gordianos se forman alrededor de la mayoría de las categorías que se pretenden erigir como pilares de la responsabilidad penal; no obstante, son relativamente escasos los escenarios en los cuales las respuestas son tan disparejas como aquellas apreciables en la discusión sobre los llamados conocimientos especiales. Con respecto al tratamiento que haya de dársele a esta figura, las posiciones encontradas en la doctrina son tan variadas como distantes entre sí.

Lo que puede percibirse en el caso de la discusión en torno al tratamiento de este tipo de conocimientos, es que al no haber consenso alguno, ni siquiera acerca de si la ausencia de su activación genera o no responsabilidad penal, las respuestas están mucho más alejadas entre sí de lo que sucede en otras discusiones. En realidad, se está muy lejos de alcanzar un acuerdo en torno a los fundamentos que permitan contestar por qué (y cuándo) sí han de ser activados, o por qué (y cuándo) no. Esto es así, porque tampoco hay acuerdo alguno en torno a lo que hay sobre la mesa de discusión. Como se dice más adelante, todo ello puede reconducir a un vacío en el debate, pues no se sabe con claridad a qué se refiere cada autor cuando emplea el término conocimientos especiales.

En este escrito, se pretende reseñar el estado actual de la discusión en torno a la ubicación sistemática del estudio de esa materia en la teoría material del delito, los límites a la exigencia de activarlos para tales o cuales casos, y las pautas a partir de los cuales han de ser diferenciados de los conocimientos ordinarios o conocimientos 
comunes. Este desarrollo tiene como fin proponer una definición general de especialidad, que permita determinar con claridad suficiente los criterios que han de emplearse a la hora de determinar cuáles conocimientos son relevantes en la determinación del deber objetivo de cuidado y cuáles no.

\section{Aclaraciones preliminares}

Antes de empezar con el desarrollo es conveniente hacer ciertas precisiones llamadas a evitar que las ideas expuestas causen malestar en el lector, producto de su falta de fundamento in extenso. En efecto, lo que con este estudio se pretende es algo muy ambicioso, pero a la vez muy limitado: lo primero, porque se busca ofrecer una noción novedosa que altere el tratamiento de la doctrina mayoritaria a los conocimientos especiales del autor; lo segundo, pues muchas de las afirmaciones esgrimidas aparecen -tomadas aisladamente- como infundadas. Ello es inevitable, pues, para fundamentar de forma adecuada cada idea en la que se apoya la presente disertación, ésta ha de ser mucho más larga (quizás del estilo de un manual). No obstante, con dichas aclaraciones se espera que dicho problema ineludible sea, al menos para efectos de este artículo, llevadero.

\section{Delimitación del estudio: ¿dolo/imprudencia, acción/omisión?}

Es cierto que "todo lo que es presupuesto común de la imputación tanto dolosa como imprudente es presupuesto del tipo objetivo" (Martínez, 1992, p. 84), sin embargo, de ello no se sigue necesariamente que todo presupuesto del tipo objetivo sea común tanto a la imputación dolosa como a la imprudente. Aún, a pesar de estar de acuerdo con la unificación del delito doloso y el delito imprudente bajo una misma estructura de imputación, éste es un tema que requiere de una fundamentación que desborda los límites de esta exploración académica. Aquí, se aborda el asunto en el delito imprudente, sin que los argumentos esgrimidos sean aplicables ipso facto al delito doloso; de hecho, muchos de los argumentos aquí esgrimidos no son aplicables cuando el autor se vale de los conocimientos especiales para desviar un curso causal existente -o para crear uno nuevo- con el fin de que desemboque en un ataque a un bien jurídico ajeno.

En cuanto a la diferencia entre acción y omisión, iguales consideraciones han de valer en aras de la concreción del trabajo. Aunque la estructura de la exposición demuestra una clara coincidencia con los 
postulados del Normativismo (o Funcionalismo Radical) (Grosso, 2006) con respecto a la unificación de la estructura de imputación de la acción y la omisión, dicha defensa no hace parte del objeto de indagación.

\section{¿Qué es un conocimiento especial?}

Varias son las fórmulas y definiciones empleadas por la doctrina para separar aquellos conocimientos especiales de otros que son comunes $\mathrm{u}$ ordinarios. Muchos emplean criterios normativos a partir de baremos como los de hombre medio, hombre prudente, buen padre de familia, etc., para caracterizar los conocimientos especiales como aquellos que superan lo que conocería "un observador sensato; el ciudadano medio que participara en la actividad en cuestión" (Serrano-González de Murillo, 2011, p. 634). Otros, en sentido similar, explican que un conocimiento especial será "aquel que supere el exigido por el Ordenamiento para cualquiera que ocupe una determinada posición jurídica dentro del tráfico jurídico" (Frisch, 2006, p. 122). A la hora de precisar dicha definición, un sector de la doctrina entiende que con el término se puede hacer referencia "tanto a los conocimientos (...) exigidos por la posición jurídica que el sujeto ocupa (sólo que poseídos en un grado superior al que resulta habitual) como a conocimientos (...) de distinta naturaleza" (Paredes, 1995 , p. 260, con cita de J. Wolter). Una corriente minoritaria, apoyada en concepciones funcionalistas sociológicas, define tal concepto como "los conocimientos que superan los propios del rol del autor" (Jakobs, 2011, p. 273).

De cualquier forma, sea cual fuere la definición adoptada, ésta debe contar con una delimitación suficiente a partir de una exposición clara y sucinta de los distintos elementos que deben ser comunes al objeto a definir. Sorprendentemente, son escasas las definiciones que vienen acompañadas de tal fundamentación previa; por el contrario, la definición de conocimiento especial no aparece como un elemento central en estudios que versan sobre el tema; de hecho, en un par de líneas superan este paso y dedican el grueso de la exposición a argumentar a favor o en contra de su relevancia en casos particulares. Pero, ¿es suficiente postular una definición sin cimentar las bases que habrán de sostenerla por encima de las otras? Gran parte de la discordia en torno a la relevancia o no de tales conocimientos parte de la falta de consenso sobre el objeto mismo de definición (Paredes, 1995, p. 24). 
Por esta razón, aquí se empieza por suponer que un conocimiento especial es, en términos generales, aquél que posee el sujeto activo a la hora de desplegar la conducta pero que dista de aquél que ordinariamente se esperaría que tuviera. Determinar cuál ha de ser el baremo que sirva para dotar de contenido a esta expresión vacía, o de qué forma ha de distar de lo ordinariamente esperado, es el objeto de esta exposición. Luego, una definición rigurosa de lo que deba entenderse por conocimiento especial es, en estos momentos, inconveniente; la razón principal es que tal noción se cimenta en la medida en que el trabajo se desarrolle y es expuesta como fundamento de la toma de postura. De esta forma, la definición ofrecida se construye a partir de la argumentación y el estudio de la doctrina relevante y no, simplemente, asumido como verdad necesaria algo que, dicho sea de paso, no suele ser raro entre los textos que estudian el particular.

\section{¿Existe alguna diferencia entre conocimiento y capacidad?}

Dicho esto, también cabe ocuparse de manera preliminar del problema encaminado a precisar si existe o no una diferencia (relevante para el Derecho penal) en los términos conocimiento y capacidad. Evidentemente, no son raras en la doctrina opiniones que abogan por un trato unificado para ambos términos, toda vez que "los conocimientos (...) determinan ya la propia capacidad del sujeto al momento de realizar la conducta" (Corcoy, 2008, p. 13; Mir, 2011, p. 299, por razones prácticas). Posturas de este corte, tienden a marcar una tenue diferencia teórica entre ambos conceptos pero, por razones metodológicas (Corcoy, 2008, p. 13) y debido a su falta de importancia práctica, los tratan como sinónimos. En este sentido, quien está mejor preparado-conoce más-probablemente tenga una mayor capacidad para controlar un curso causal particular: por eso, el corredor de fórmula uno que tenga mayor conocimiento sobre el funcionamiento de su motor, el rendimiento de sus neumáticos y las condiciones de humedad de la pista, tendrá una mayor capacidad para ganar la carrera (Quintero, 1989, p. 122).

No obstante, otro sector de la doctrina resalta el hecho de que, si bien los conocimientos sobre las circunstancias fácticas en las cuales se ve envuelta la conducta determinan el grado o la capacidad de controlar o evitar un posible resultado, no es cierto que ante igualdad de conocimiento, las capacidades no sean relevantes a la hora de controlar la producción de un posible resultado (Paredes, 1995, p. 
261). Es decir, aun cuando la representación de dos sujetos sobre las condiciones fácticas que rodean su conducta sean las mismas, de todos modos la posibilidad de control sobre el curso causal puede ser distinta en razón de sus capacidades individuales. Podría pensarse por esto que no es adecuado unificar bajo un mismo rótulo las capacidades técnicas y los conocimientos especiales, ni siquiera por razones metodológicas.

Otra razón adicional para la separación entre ambos conceptos es que "ciertamente, en muchas ocasiones el grado de conocimiento sobre la situación y el de capacidad técnica para afrontarla están interrelacionados: frecuentemente el sujeto más preparado -con más capacidades- percibe mejor la situación; $y$, sin duda, un buen conocimiento de la situación es condición imprescindible para poder ejercer las propias capacidades de control de la misma. No obstante, dicha interrelación no es mecánica e incluso, a veces, no existe: el conocimiento que un cirujano tenga acerca de la clase de operación quirúrgica que sería necesaria para salvar al paciente, por muy exacto que sea, no le capacita por sí solo para realizar dicha intervención; e igualmente, la capacidad para realizar un tratamiento médico puede ver menoscabada su eficacia por el desconocimiento de algún factor adicional de riesgo inherente a dicho tratamiento" (Paredes, 1995, p. 261).

En este sentido, Paredes (1995) hace una distinción -que en principio parece muy oscura- entre conocimientos y capacidades para explicar que en tanto los conocimientos "serán en principio relevantes en todo caso a efectos de determinar el deber de conducta" (p. 261), la utilización de las capacidades especiales ha de quedar a la discreción del sujeto, pues "al actuar dentro del ámbito del riesgo permitido, su actuación, ejercitadas las capacidades normalmente presupuestas, sería lícita en cualquiera de los casos" (Paredes, 1995, p. 265). Es decir, al sujeto se le puede exigir que actúe con todos sus conocimientos, pero no que haga uso de todas sus facultades. Esto lleva a una paradoja, pues no parece ser claro qué opción debe acogerse en casos en los cuales las capacidades están dadas en términos de conocimientos: si a un médico se le exige que utilice todos sus conocimientos, pero no sus capacidades, ¿qué debe hacer cuando para salvar a un paciente debe implementar una técnica que sólo él es capaz de aplicar, porque sólo él la conoce? Parece haber en esta argumentación una contradicción insuperable. Se utiliza el ejemplo del médico pues el propio Paredes (1995) se basa en él para argumentar su posición una vez ha afirmado que "la capacidad para 
realizar un tratamiento médico puede verse menoscabada en su eficacia por el desconocimiento"(p. 261 y 266) -con lo cual sugiere que dado que debe emplear sus conocimientos al máximo, ha de emplear su especial capacidad al máximo- , y otra vez para aseverar que "el cirujano que domina una técnica quirúrgica novedosa puede utilizarla si lo desea (...) pero el ordenamiento jurídico no debe obligarle a ello (p. 261 y 266)".

Sin embargo, la razón principal esgrimida a favor de tal diferenciación es que es mucho más factible una variación de esos conocimientos durante el curso de una acción que la de las aptitudes técnicas que la sustentan (Corcoy, 2008, p. 22; Paredes, 1995, p. 265). Aunque es cierto que algunos de los conocimientos son fácilmente adquiridos (como enterarse de que el conductor del tren está borracho porque se escuchó a dos personas hablar de eso), difícilmente puede sostenerse qué conocimientos de orden más técnico (como entender a cabalidad cómo funciona el sistema de enfriamiento de motor de un carro arrendado) se den de un momento a otro. Éstas y otras aparentes paradojas surgen a causa de la falta de delineación entre conocimientos especiales en razón de la materia sobre la cual tratan, de un lado, y conocimientos especiales en virtud de la forma como son adquiridos, de otro. Parece, pues, conveniente que a la hora de definir la idea de conocimiento especial, se distinga entre conocimientos adquiridos por puro azar-esto es, con independencia de la posición jurídica que ocupa el sujeto activo- y los que son fruto de la posición jurídica ocupada por el sujeto, a fin de que se entienda la idea de especialidad propuesta.

En definitiva, tiene razón la doctrina mayoritaria cuando afirma que la distinción entre conocimientos y capacidades tiene relevancia principalmente en el ámbito metodológico; por esta razón, con base en el enfoque de Corcoy (2008, p. 13), cuando aquí se hable de conocimientos no debe entenderse como una oposición en la cual lo dicho no aplica para las capacidades del sujeto activo. Por el contrario, y a menos de que de forma expresa se advierta así, las consideraciones sobre los conocimientos especiales atañen también a las capacidades especiales, teniendo en cuenta las reservas que se expresan a continuación.

\section{¿Máximos o mínimos?}

Además de la anterior diferencia, según una parte de la doctrina, es evidente que por establecerse un nivel mínimo (presupuesto a las 
capacidades del sujeto que ocupa la posición jurídica) no se deriva la prohibición para éste de actuar utilizando tales capacidades superiores (Paredes, 1995, p. 264). Esto implica que "la conducta del conductor de rallies, que conduce por una carretera comarcal como si se tratase de una competición, puede no constituir todavía una imprudencia, debido a sus mayores capacidades de control del vehículo frente a imprevistos" (Paredes, 1995, p. 265).

Este punto de vista sirve para introducir una precisión metodológica importante: cuando se estudia la relevancia de los conocimientos especiales en la delimitación del contenido del deber de cuidado, jamás se pregunta por el máximo de permisibilidad sino por el mínimo de exigencia. Aclarar esto es relevante pues pueden apreciarse dos casos límite problemáticos: el primero, aquél en el cual ante la constatación de conocimientos especiales se pretende aumentar el margen del riesgo permitido en favor del sujeto activo; el segundo, aquél en cuya virtud ante la ausencia de aplicación de los conocimientos especiales se pretende extender el límite de lo exigido por el deber objetivo de cuidado, en perjuicio del sujeto activo.

El caso de un conductor de rallies, que a causa de su especial entrenamiento tiene un mayor margen de control sobre la producción de resultados lesivos en actividades riesgosas (como es la de conducción a exceso de velocidad), no se corresponde con lo estudiado. La pregunta por el caso en que a causa de tal exceso de velocidad -y a pesar de su especial capacidad- lesione a otra persona, no es directamente el objeto de las presentes reflexiones. Sí lo es, en cambio, la situación en la cual pese a conducir dentro del límite de velocidad permitido omite utilizar sus capacidades especiales y lesiona a otra persona pudiendo (y debiendo) evitarlo.

El punto de partida no está en si a mayor conocimiento hay más permisión en el deber de conducta, sino en si a mayor conocimiento hay más exigibilidad en dicho deber. No se trata, se repite, del estudio del contenido del límite máximo a la hora de riesgo permitido, sino del límite que establece lo mínimo exigible a una persona para ser juzgada por un delito imprudente. En el primer caso, la utilización de los conocimientos especiales es un presupuesto del problema; en el segundo, su omisión es el problema.

\section{¿Dónde debe ubicarse el estudio de los conocimientos especiales?}

Surge también otro problema preliminar cual es el atinente a la ubicación de los conocimientos especiales en el estudio de la teoría 
material del delito. Hay quienes optan por la tipicidad o la culpabilidad, mientras que un importante sector doctrinario entiende que es un problema de antijuridicidad; desde luego, según la ubicación adoptada los argumentos serán distintos y las conclusiones pueden ser radicalmente opuestas.

Sea lo primero, decir que la ubicación de los conocimientos especiales en sede de tipicidad, antijuridicidad o culpabilidad, depende, en gran medida, de la concepción de la teoría del delito que se adopte. Bajo un esquema causalista, en el cual el dolo hace parte de la culpabilidad, los conocimientos especiales no podrían ser tratados en otra sede que no fuera ésta. Para el Finalismo, en cambio, habiéndose desplazado el aspecto cognoscitivo fáctico junto con el volitivo del dolo hacia la tipicidad, el problema de los conocimientos especiales es esencialmente típico. Igualmente, en atención a la concepción que se tenga sobre la relación entre la tipicidad y la antijuridicidad, el problema recaerá sobre una u otra, o sobre ambas.

Dicho esto, cabe notar que una gran parte de la doctrina que aborda el problema de los conocimientos especiales lo hace solo con el fin de determinar cuándo han de incluirse en el juicio de responsabilidad, conocimientos superiores al promedio que el sujeto activo tenía al momento de llevar a cabo su conducta. En efecto, es común que el término en cuestión sea empleado para referirse a "aquel que ha tenido acceso a hechos que sobrepasarían los conocidos por el observador objetivo" (Serrano-González de Murillo, 2011, p. 634). Sin embargo, la especialidad no supone per se superioridad y nada se opone a que los conocimientos especiales estén dados también por una especial deficiencia en el aspecto cognitivo. Tales casos, han llevado a un sector de la doctrina a argumentar que el problema de los conocimientos especiales debe ser analizado en sede de culpabilidad, teniendo en cuenta que se trata de la valoración del poder subjetivo del autor para ajustar su conducta a la norma de cuidado.

Al respecto, Mir (2011) explica que cabe diferenciar dos ámbitos de la problemática en torno a los conocimientos o capacidades del sujeto activo: puede estarse frente a conocimientos y capacidades superiores al promedio, caso en el cual habrán de incidir sobre la antijuridicidad de la conducta; o puede estarse frente a conocimientos y capacidades inferiores al promedio, caso en el cual deben ser tenidos en cuenta en el juicio de culpabilidad (p. 300). Por ello, señala: 
...una capacidad inferior del sujeto no imaginable en una persona mentalmente normal (reflejos demasiado lentos, capacidad intelectual inferior, etc.) no puede excluir o disminuir la antijuridicidad, sino sólo puede producir la exclusión o atenuación de la imputación personal de la objetiva norma de cuidado (Mir, 2011, p. 297).

Aunque pueda ser cierto que en tales casos se está frente a una posible disminución de la culpabilidad, o su exclusión, en la concepción de conocimientos especiales aquí ofrecida el énfasis nunca se pondrá sobre una especial discapacidad cognitiva, o eventos semejantes que justifiquen una particular consideración en torno a la capacidad de motivarse con respecto a la norma, o de comportarse de acuerdo a ella. Por el contrario, deben estudiarse aquellos casos en los cuales puede constatarse que el autor cuenta con una base cognitiva -fáctica o normativa-dada por un conocimiento superior al promedio, que le permite comportarse conforme a una representación de la realidad, que no es accesible al común de las personas que ocupan su cargo o posición.

Sin embargo, históricamente no han sido pocas las posturas que equiparan mayores o menores capacidades a la hora de abordar el problema de los conocimientos especiales, ubicándolo siempre en sede de culpabilidad. Así, concepciones de corte causalista que incluyen el dolo en esa sede, ubican el problema de las mayores capacidades o conocimientos del sujeto activo allí, con lo cual es un asunto irrelevante tanto para la tipicidad como para la antijuridicidad. En este sentido, autores que optan por la sede de culpabilidad afirman que, como regla general, han de ser aplicados por el sujeto activo (Cobo del Rosal y Vives, 1999, p. 646), pero también hay quienes afirman lo contrario (Cfr. Torío, 1974, p. 33).

Otra corriente, de corte finalista, se inclina por aceptar la ubicación del dolo en sede de tipicidad, pero mantiene que la discusión en torno a la obligación de activar o no los conocimientos especiales es natural a la antijuridicidad (Mir, 2011, p. 296-297). En general, autores que conciben una relación de ratio cognoscendi entre la tipicidad y la antijuridicidad suelen trazar una fuerte división entre ambas categorías del juicio de responsabilidad. En este sentido, suele argumentarse que el problema de los conocimientos especiales es uno que atañe a la antijuridicidad, aisladamente de la tipicidad. Así, el injusto del delito imprudente ha tenido como fundamento la idea de que "la infracción del objetivo deber de cuidado exigible en el tráfico (según la fórmula del parágrafo 276 
del Código civil alemán) condiciona ya la antijuridicidad (...)" (Mir, 2011, p. 296). Autores que se casan con esta corriente (Huerta, 1984, p. 119), afirman que, siendo la pregunta si en dado caso de que no se aplique un conocimiento especial se vulnera o no un interés jurídico, el problema no pertenece al juicio de tipicidad sino a la esfera de antijuridicidad; así, se afirma: "quien podía haber actuado con mayor prudencia que el hombre medio y con ello evitar el resultado, debió hacerlo, y si no lo hizo actuó antijurídicamente" (Stratenwerth, 2000, 15-21; Mir, 2011, p. 300).

No obstante, una gran parte de la doctrina que ubica el problema como atinente a la antijuridicidad suele manejarlo bajo el concepto global de injusto personal. Con esto, se suelen ver la tipicidad y la antijuridicidad como un holismo descriptivo pero también valorativo en el cual ambas nociones configuran un primer criterio en la teoría material del delito. Aunque hay gran divergencia entre la relación en la que se encuentra la antijuridicidad y la tipicidad ${ }^{1}$, pocos hoy aún sostienen que son figuras categóricamente aisladas entre sí. En realidad, la doctrina que ubica el problema de los conocimientos especiales sin referencia a la tipicidad es hoy muy escasa.

Por estas razones, el desarrollo más importante de esta figura entre la doctrina mayoritaria hoy en día se da bajo el presupuesto de que el problema debe abordarse al menos parcialmente en sede de tipicidad ${ }^{2}$. De hecho, el grueso de la discusión actual sobre la ubicación sistemática de esta figura dentro de la teoría material del delito se encuentra entre quienes mantienen pautas ontológicas para situar esta figura en el tipo objetivo o subjetivo, frente a quienes abogan por la introducción de criterios normativos como el de riesgo jurídicamente desaprobado y deber de cuidado, con independencia de dichas categorías.

Como anotación preliminar, cabe aclarar que aquí no se mantiene una división tajante entre tipo objetivo y tipo subjetivo basada en criterios ontológicos. Por el contrario: lo objetivo o subjetivo de la conducta, y, en particular de la imputación, debe estar dado por criterios de índole normativo. Lo que interesa en una valoración objetiva de la conducta es determinar si hubo o no un ataque indebido al bien jurídico objeto de protección, lo que empieza con la verificación de si se creó un riesgo jurídicamente desaprobado (Serrano-González de Murillo, 2011, p. 629; Reyes, 2002, p. 538), entendido éste como una violación al deber objetivo de cuidado. 
Por eso, el estudio de los conocimientos especiales del sujeto activo, teniendo como referencia el deber objetivo de cuidado, se enmarca dentro de la imputación objetiva lejos de todo contraste entre criterios ontológicos de objetivo y subjetivo. De acuerdo con el profesor Reyes, el concepto tradicional de injusto puede ser abarcado (en su totalidad) por la imputación objetiva, con lo cual desaparece la distinción ontológica que la doctrina dominante suele hacer entre tipo objetivo y tipo subjetivo (2002, p. 53). En este sentido, lo objetivo (de la imputación objetiva) no está dado por los mismos criterios ontológicos utilizados para separar el tipo objetivo del tipo subjetivo. Por el contrario, debe estar dado por una comparación entre el comportamiento del sujeto activo y un estándar normativo como punto de partida a la hora de evaluar su conducta, en la cual confluyen los elementos que tradicionalmente habían sido diferenciados como objetivos y subjetivos.

\section{Riesgo jurídicamente desaprobado, deber de cuidado y conoci- miento especial desde una perspectiva normativa}

Al abordar el problema de los conocimientos especiales, gran parte de la doctrina suele enfrentarlos con la figura del riesgo jurídicamente desaprobado (bien sea para abordarlos desde esta perspectiva, o para criticar la imputación objetiva como teoría adecuada para resolver dicha cuestión), de cara al deber objetivo de cuidado. Y, aunque en la actualidad hay cierto consenso entre los partidarios de la teoría de la imputación objetiva con respecto a la ubicación del problema del deber de cuidado dentro de la categoría de riesgo jurídicamente desaprobado, como se dirá luego, tal coincidencia desaparece por completo a la hora de definir qué se entiende por riesgo jurídicamente desaprobado o, cómo éste habrá de determinarse para casos concretos. En efecto, para referirse al particular, varias son las definiciones que aparecen en la doctrina, por ejemplo: "riesgo tolerado" (Frisch, 2004, p. 19), "riesgo adecuado" (Jescheck, 1981, t. I, 523), "riesgo socialmente adecuado" (Cancio, 1994, p. 28), "riesgo consentido" (Hirsch, 1993, p. 32, quien basado en tal caracterización, tiende a enfocar la discusión en torno a la antijuridicidad del injusto), entre muchas otras.

Sin embargo, en algunas ocasiones la doctrina es tan vaga a la hora de precisar el contenido del riesgo jurídicamente desaprobado, que tal figura se considera como "expresión vacía de contenido, que encubre bajo nuevas formas conceptos ya conocidos (antijuri- 
dicidad, imprudencia, imputación del resultado,...), y que lo hace además de una forma poco diferenciada, aportando así más confusión que claridad" (Paredes, 1995, p. 273; Mir, 2011, p. 24). En efecto, siendo el debate sobre la exigibilidad en la aplicación de conocimientos especiales en la conducta del sujeto activo uno que trata esencialmente sobre cuándo se entiende que el sujeto ha cumplido su deber de cuidado -o cuándo éste ha creado un riesgo jurídicamente desaprobado- es menester, si se quiere estudiar la figura de los conocimientos especiales, antes reflexionar acerca de la incidencia que tiene el cómo entendamos el deber de conducta sobre los argumentos empleados para abogar a favor de la obligación de activar los conocimientos especiales del autor. Pues, en gran medida y en atención a qué ha sido entendido por deber objetivo de cuidado, históricamente la doctrina se inclina a favor o en contra de la obligación de activar los conocimientos especiales del autor.

Al intentar delinear el riesgo permitido de su contraparte, la doctrina implementa distintos modelos normativos a través de los cuales se intenta establecer cuál es el patrón de conducta exigible de cualquier individuo ante tal o cual circunstancia. Con ello, se abre el debate en torno a cuál debe ser el modelo que agrupe el conjunto de expectativas que el Estado impone sobre las personas en la configuración de las normas que rigen la vida en sociedad.

Entre dichos modelos, se encuentran en la doctrina los de evitabilidad individual o eficacia causal, para las cuales "el deber de conducta consiste en hacer todo lo posible para evitar la realización del desvalor de resultado" (Paredes, 1995, p. 256, quien hace citas de Hippel, Exner, Oheler, Hardwig, Blei y Rodríguez Devesa). Dentro de dichos modelos, se encuentra un sinfín de posturas que confunden la posibilidad causal de evitar con la exigibilidad jurídica de evitar (Mir, 2011, p. 297; Jescheck, t. I, 1981, p. 523). Con ello, imponen al individuo la exigencia de evitar a toda costa la producción de resultados disvaliosos, con lo cual la pregunta acerca de cuándo deben y cuándo no, aplicarse los conocimientos especiales, carece de mayor utilidad. La respuesta es obvia: siempre que se tengan, han de aplicarse los conocimientos que lleven a la no producción del resultado lesivo independientemente de su naturaleza.

Otros, consideran que el modelo a imponer, debe partir de la consideración según la cual a nadie le es reprochable evitar todo riesgo que su conducta pueda generar para los bienes jurídicos ajenos. Bajo el entendido de que la sola causalidad no era suficiente para 
determinar cuándo han de aplicarse los conocimientos especiales, otra corriente parte de la tesis según la cual el contenido del deber jurídico sólo puede encontrarse en la sociedad, siendo ésta la que -materialmente- contenga el estándar que debe ser utilizado para determinar cuándo la omisión en la aplicación de un conocimiento especial comporta el desvalor de una conducta antijurídica (Piña, 2005, p. 395). Lo que une a todas estas teorías es que la figura que usan para determinar el contenido del deber de conducta es, esencialmente, sociológica. Lo que las separa es cuál deba ser, en concreto, el molde usado para determinar la norma social: "hombre medio" (Paredes, 1995, p. 314, quien cita a Hippel, Maihofer, Art. Kaufmann, Mayer, Octavio de Toledo/Huerta Tocildo y Corcoy Bidasolo, tan sólo en relación con "sectores de actividad no reglamentados"), "hombre medio ideal" (Maurach, 1962, p. 237)", "hombre prudente" (Welzel, 1993, p. 79; Arm. Kaufmann, 2006, p. 122; Jescheck, 1993, p. 255; Roxin, 1997, p. 209; Muñoz, 2010, p. 442), a veces también llamado "diligente", "racional" o "inteligente" (ver citas de Reyes, 2002, p. 116 nota 15), "hombre prudente puesto en la posición del autor" (Mir, 2011, p. 300) ${ }^{4}$, etc.

En esta oportunidad, se defiende la vigencia de la figura del rol social como el modelo a partir del cuál ha de determinarse la extensión de la permisión del riesgo y, con ello, el paradigma a partir del cuál ha de determinarse cuáles conocimientos debe aplicar el autor dadas ciertas circunstancias y cuáles han de permanecer como "mera subjetividad carente de interés jurídico" (Jakobs, 1998, p. 48). Esto sólo es posible si antes se ha aceptado la vigencia de la teoría de la adecuación social como prisma a través del cual se configuran $\mathrm{y}$ entienden las relaciones sociales en nuestro actual modelo de Estado.

Según la formulación original de la mencionada figura, atribuida a Welzel, hacia finales de la década de 1930 del siglo pasado, "quedan fuera del concepto de injusto todas aquellas acciones que se mueven funcionalmente dentro del orden históricamente constituido" (Cancio, 1994, p. 13, con citas de Welzel). En palabras suyas, "la adecuación social es el 'significado social' de un comportamiento de no estar prohibido; por ello, este comportamiento tampoco puede constituir un injusto personal [pues] éste, según Welzel, sólo comienza una vez traspasada la frontera de la adecuación social" (Cancio, 1994, p. 14). Esto implica, que para poder reputar un comportamiento como injusto antes debe encontrarse en contradicción 
con los intereses sociales. Es, en principio, la sociedad la que dicta cuándo un ataque a los intereses jurídicamente protegidos ha de considerarse aprobado (o tolerado) y cuándo no.

Lo primero que habría de decirse, es que-independientemente de que tal principio de adecuación social "haya sido sometido por sus mismos defensores a un permanente zarandeo, muy especialmente por lo que hace a la naturaleza jurídica y función sistemática de tal principio, que sin duda ha contribuido a oscurecer la discusión" (Roxin, 1997, p. 114)- aquí se pretende solo señalar unos esbozos generales acerca de lo que supone esta figura. Por esta razón, no se abordan problemas más específicos como qué función debe cumplir o cuál es su ubicación sistemática dentro de la teoría material del delito; sobre el particular hay tantas opiniones cuantos autores escriben el respecto (para una visión condensada de la disputa ver: Reyes, 2005, p. 89).

Lo que sí es relevante, entonces, es la importancia de la adecuación social como criterio interpretador del tipo y más concretamente del deber de conducta a partir de una correspondencia con los intereses sociales y la norma social imperante de comportamiento. En este sentido, se expresa que "a la hora de interpretar el tipo penal, y en concreto, al interpretar el contenido del desvalor objetivo de acción del mismo, aquellos usos sociales o este principio de adecuación (...) actúan como criterio interpretativo principal, sino único, del mismo" (Paredes, 1995, p. 313, con un recuento in extenso en la nota 36 de quienes sostienen esa postura). Siempre que se intente delinear el deber de conducta predicable de toda persona que realice actividades riesgosas, cobra plena relevancia la consideración según la cual "si a la hora de todo contacto social todos hubiesen de tener en cuenta todas las consecuencias posibles desde el punto de vista cognitivo, la sociedad quedaría paralizada" (Jakobs, 1996, p. 18).

De entrada, se tiene un primer gran filtro: ninguna conducta considerada socialmente adecuada o "socialmente usual" (Bustos, 1987, p. 224) puede, bajo ningún punto de vista, constituir una violación al deber objetivo de cuidado. Esto es lo que se denomina el "criterio delimitador del principio de adecuación social" (Maurach, t. 1, 1962, p. 189) que -dicho sea de paso- no funciona en sentido contrario; así, ha dicho Roxin (1997) que "la inadecuación social es en todo caso una calificación a predicar de la conducta delictiva como un todo; no es, sin embargo, éste un factor que opera concretamente dentro del núcleo del proceso de determinación de 
la antijuridicidad". La relevancia de considerar a la sociedad como fundamento primitivo de todo juicio de desvalor radica en que el problema de qué sea entendido por deber objetivo de cuidado, y con ello de cuáles han de ser los parámetros implementados a la hora de determinar la exigencia de aplicación o no de conocimientos especiales, es un asunto que desborda por completo el pequeño marco que supone la regulación legal (p. 115).

Luego, las pautas para determinar bajo qué casos se está ante la obligación de activar los conocimientos especiales, en contraposición a aquellos en los cuales el sujeto no está obligado jurídicamente a aplicarlos, escapan de la esfera de la norma legal positiva y se reivindican como preguntas cuyas soluciones necesariamente deben surgir de la sociedad misma. De entrada, se tiene como fundamento que sólo lo socialmente inadecuado puede constituirse eventualmente como delito; es decir, la desaprobación social es un requisito necesario más no suficiente para la constatación de la desaprobación jurídica de un riesgo.

\section{La determinación del deber objetivo de cuidado desde la teoría de los roles sociales.}

La experiencia social es, entonces, la fuente primaria a la hora de determinar la frontera entre lo aprobado y lo desaprobado por el Derecho en general, y por el Derecho penal en particular. Por ello, un sector de la doctrina apunta a una equivalencia entre el concepto de riesgo permitido y el de la estructura del rol social (Ruiz, 2011, p. 223). En este orden de ideas, quien se mantiene dentro del rol y lo ejecuta de manera adecuada no traspasa el riesgo permitido (con independencia de las malas intenciones y voliciones presentes en su 'fuero interno') (Piña, 2005, p. 398). No parece evidente el hecho de que toda regulación del Derecho penal esté contenida en las normas positivas propias del Ordenamiento. Por el contrario, parece más claro el hecho de que gran parte de las normas que rigen el funcionamiento de una sociedad están dictadas por ella misma en su origen ${ }^{5}$.

La sociedad es, pues, el motor del cambio del Derecho: conductas que antaño eran mal vistas frecuentemente eran delictivas $y$, con el correr de los años, han perdido ese estatus en la medida en que la sociedad cambiante se ha mostrado -al menos- tolerante frente a ellas. De hecho, en repetidas ocasiones los delitos desaparecen, aparecen o son modificados en los códigos penales únicamente 
motivados por el vaivén de la reacción social ante ciertas conductas; al respecto, no sobra recordar los ejemplos del estupro, la bigamia, la sodomía, etc. que la doctrina colombiana frecuentemente cita para justificar la subordinación del Derecho -y en particular del Derecho penal- a los intereses de la sociedad. La verdad sea dicha, quien dice defender la independencia del Derecho frente a la sociedad, pero igualmente acepta el papel determinante que juega ésta en la transformación de aquél, no dista del niño que se jacta ante sus amigos de 'hacer lo que se le viene en gana... cada vez que su madre le da permiso'.

Así las cosas, tal y como lo esboza Cancio, en toda sociedad moderna pueden señalarse dos tipos de casos en los cuales el deber objetivo de cuidado no está dado por normas jurídicas sino por normas sociales de relevancia jurídica. El primero, es aquél en el cual el deber objetivo de conducta está claramente delimitado por "el conjunto de normas consuetudinarias sobre la correcta actuación en un determinado oficio o profesión (lex artis)" (Cancio, 2001, p. 99). El segundo, es aquél en el cual "habrá que recurrir al juicio de valor hipotético de cómo habría actuado en el caso concreto, ex ante, un tercero prudente e imparcial (un buen y diligente padre de familia, un empresario responsable, o similar)" (Cancio, 2001, p. 99).

El contacto social es la base de toda determinación del deber objetivo de cuidado, pues el carácter dinámico del bien jurídico está dado por su ámbito eminentemente social (Cancio, 1994, p. 33). Siendo esto así, no puede desligarse el concepto del riesgo permitido del adecuado cumplimiento de las exigencias impuestas a las personas, discriminadas según el rol social que desempeñen en la sociedad. Pues, tal y como lo expone un sector doctrinario, se debe entender el riesgo no permitido como referente al desconocimiento de los parámetros impuestos al rol normativo dentro del cual el agente debería desempeñarse de acuerdo con lo instaurado ya sea por una reglamentación expresa o sin ella (Montealegre, 1988, p. 32). Luego, para que exista una violación al deber objetivo de cuidado debe constatarse previamente una defraudación de las exigencias impuestas por el Ordenamiento a la persona, pero sólo en tanto portadora de un rol social, que es uno de los principios básicos del esquema trazado por G. Jakobs en distintos escritos (1997b, p. 167).

Por tal razón, Reyes explica que determinar si un riesgo es jurídicamente desaprobado no depende de una consideración genérica de la actividad generadora de peligros, como pretendió la 
figura del hombre prudente, sino del análisis de la posición concreta (rol social) en que se encontraba el autor (2005, p. 126). Según él, hay tres pautas a tener en cuenta: a) qué debe saber cada individuo, lo que depende del papel social que desempeña el autor; b) qué sabe efectivamente (referente a conocimientos especiales); y c) qué debe hacer el autor con base en su conocimiento (Reyes, 2005, p. 126).

En consecuencia, la creación de un riesgo jurídicamente desaprobado implica el desarrollo de una conducta diferente de la que se espera de un ser social en las mismas circunstancias (Ruiz, 2011, p. 191). Por ende, lo importante no es lo que ocurre en la mente de ese ser humano como tal, sino la comparación de la conducta efectivamente desarrollada con la que cualquier otra persona en su lugar y dentro de un rol específico debe desarrollar (Reyes, 2002, p. 5; Reyes, 2005a, p. 534).

Sin embargo, en el delito culposo, la doctrina opta por valorar el aspecto subjetivo de la conducta basándose en un criterio fundamental: el deber de prever el peligro o el resultado disvalioso de la conducta imprudente. Así, existen quienes incluyen este aspecto como único elemento a valorar dentro del aspecto subjetivo del delito imprudente (Baumann, 1973, p. 120; Exner, 1957, p. 173; Radbruch, 1955, p. 201), hasta quienes lo ubican como apenas uno de los múltiples elementos a valorar en este aspecto (Corcoy, 2008, p. 22; Engisch, 2008, p. 82; Jescheck, 1993, p. 248; Kaufmann, 2006, p. 213; Mir, 2011, p. 299; Quintero, 1989, p. 168; Rodríguez, 1978, p. 322; Stratenwerth, 1976, p. 98; Wessels, 1980, p. 132)

Lo cierto es que en una concepción normativa de la teoría del delito, el análisis de la conducta del ser humano como ser social o portador de roles, debe ser considerado parte del aspecto objetivo de la misma (Cancio, 2005, p. 210; Reyes, 2005, p. 70; López, 2005, p. 130; Ruiz, 2011, p. 191); si la conducta cumple con las expectativas que se esperan de esa persona en desarrollo de un rol, será irrelevante para el Derecho penal. Luego, el problema no está en si en la imputación objetiva deben abordarse elementos subjetivos o no. Como ya se ha dicho antes, hay que mantener cierta claridad al emplear términos como objetivo o subjetivo, pues en atención a qué perspectiva se adopte para definir estos términos se puede llegar a conclusiones que al parecer suenan incoherentes.

Así las cosas, con el profesor Reyes (2005), puede afirmarse que lo objetivo de la imputación objetiva consiste en un criterio 
normativo según el cual dentro del injusto interesa siempre la conducta de la persona, pero no considerado como individuo, sino como un portador de roles del cual se esperan determinadas formas de comportamiento (2005, p. 71). Cancio, por su parte, señala que objetivo "significa concreción de la norma conforme a los parámetros generales de un sujeto en un determinado papel social" (p. 223).

En cuanto a lo que deba entenderse por subjetivo, Reyes (2005b) concreta la relación entre ambos aspectos del juicio de imputación de esta forma: "mientras lo objetivo será el estudio de la conducta del hombre en cuanto ser social, lo subjetivo hará referencia al análisis del comportamiento del hombre en cuanto individuo" (p. 198). En la parte subjetiva de la imputación es "en donde este lado subjetivo del hecho vincula la acción del autor con el tipo objetivo (empleando los términos tradicionales) en un contexto normativo de valoración social" (Ruiz, 2011, p. 190). En tal aspecto subjetivo de la imputación habrán de estudiarse, pues, algunos de los presupuestos antes ubicados en la culpabilidad como son la capacidad del individuo de comprender la norma y de motivarse conforme a ella; ello, con la advertencia de que la ubicación del dolo y la imprudencia no hace parte de la imputación subjetiva, sino del aspecto objetivo de la misma (Reyes, 2005a, p. 534).

Basada en estos criterios la doctrina afirma que "si se quiere determinar desde el punto de vista objetivo lo que está prohibido, el fruto de esa delimitación no puede apartarse de lo que está prohibido para cualquier sujeto ante determinada situación" (Serrano, 2011, p. 641). Esto no implica abandonar el estudio de elementos pertenecientes a la psiquis del sujeto activo en el juicio objetivo, sino dejar de lado todo elemento -mental o no- que no esté previsto de manera general como relevante para evaluar la conducta de cualquier persona que se enfrente a una misma y determinada situación.

Luego, dentro de la imputación objetiva sí cabe el estudio de elementos mentales o psicológicos, como lo son los conocimientos exigibles al portador de determinado rol social. Como tal, para evaluar la conducta objetivamente, deben tenerse en cuenta tanto aspectos externos como internos en el actuar del sujeto activo, siempre considerado en tanto portador de roles sociales. Así lo explica Jakobs (1997) cuando afirma que el incluir conocimientos en el rol específico no altera para nada el juicio objetivo que se hace dentro de la imputación objetiva (p. 82). 
Dicho esto, es momento de delinear una definición que tenga como base los argumentos aquí esgrimidos a la hora de postular un parámetro claro para diferenciar aquellos conocimientos que han de ser aplicados por el autor, de aquellos cuya omisión no generaría ningún reproche jurídico-penal.

\section{¿Qué hace a un conocimiento especial?}

Deben ahora introducirse dos axiomas que han de tenerse muy en cuenta. El primero: no hay conocimiento especial sin rol social; esto se debe principalmente a que -como se verá- el rol social es la figura a partir de la cual ha de juzgarse cuándo un conocimiento es especial y cuándo es ordinario. Luego, de no existir esta pauta, sería imposible realizar tal distinción. El segundo: como regla general, no debe exigirse la aplicación de ningún conocimiento especial en el ejercicio de un rol social; este deriva del primero y supone que, siendo especial aquél conocimiento ajeno al propio del rol social, no ha sido incluido dentro del conjunto de exigencias que el Estado impone a cualquiera que ocupe tal posición.

A continuación, es necesario explicar qué ha de entenderse por conocimiento especial para que tales axiomas se entiendan con claridad y se disipe la connotación de radicalidad que en un primer momento aparentan.

En cuanto a la materia: especial es aquel conocimiento ajeno al rol social que el sujeto activo desempeña, tanto por su naturaleza como por el grado.

Lo primero que debe abordarse es cuándo puede predicarse la especialidad material de un conocimiento.

El primer aspecto a tratar para poder delinear el criterio que ayude en tal tarea, atañe a la naturaleza del conocimiento respecto de aquél esperado de una persona apta para desempeñar tal o cual función en la sociedad. Así las cosas, con base en un sector de la doctrina, para que un conocimiento pueda calificarse como tal debe al menos concurrir el siguiente factor: "[que] ese conocimiento o facultad especial se encuentre directamente relacionado con el rol que desempeña" (Ruiz, 2011, p. 192); se supone que, según la materia del conocimiento, lo que el autor sepa o ignore puede estar relacionado con su posición jurídica dentro del tráfico jurídico o puede no estarlo. Esta es, pues, la primera distinción que debe hacerse: sólo es 
especial aquél conocimiento que por su naturaleza puede predicarse como exento del conjunto de exigencias que el Estado impone a un determinado cargo en un sector del tráfico jurídico preciso; por tráfico jurídico debe entenderse el conjunto de sectores en los cuales se desenvuelve la actividad social con relevancia jurídica; esto es, el conjunto de roles que puede desempeñar una persona en la sociedad y que son de interés para el Ordenamiento en tanto que su actividad se encuentra en alguna medida reglada por normas jurídicas.

En efecto, el Estado 7 impone determinadas obligaciones jurídicas a ciertos agentes que desempeñan determinadas posiciones dentro del tráfico jurídico (Ruiz, 2011, p. 190); esto es, las normas van dirigidas a ciertos sectores del tráfico jurídico (Silva, 1992, p. 36), $\mathrm{y}$, con ello, a indiscutibles personas que se mueven dentro de tales sectores. Por ejemplo, una regla jurídica que diga que se prohíbe la conducción de vehículos automotores a más de $80 \mathrm{~km} / \mathrm{h}$ en calles aledañas a barrios residenciales, está dirigida hacia un sector determinado dentro del tráfico jurídico, a saber: los conductores. No tiene ningún sentido predicar obligatoriedad de ella respecto a los peatones quienes, difícilmente, podrán superar tal velocidad en su condición de tales. De igual forma, es dudoso que las normas que dictaminan la forma cómo los peatones deben cruzar la acera en calles urbanas (por la cebra y cuando el semáforo peatonal esté en verde, por ejemplo) esté destinada a alguien más que a los peatones en tanto transeúntes ${ }^{8}$.

Luego, si el Ordenamiento jurídico impone ciertas obligaciones a determinados sectores, y a otros tantos otras, los conocimientos exigibles al autor no pueden desconocer esta tendencia. De hecho, difícilmente puede considerarse válido exigirle a un conductor de vehículo automotor conocimientos especializados en ingeniería mecánica; a pesar de que si todos los conductores se cercioraran de las condiciones mecánicas de su carro todas las mañanas, su actividad sería considerablemente menos riesgosa para la vida de las demás personas. Igualmente, no parece adecuado exigir al salvavidas de una piscina que posea la destreza de un nadador medallista olímpico, aun cuando esto reduciría de forma significativa el riesgo de ahogamiento en piscinas públicas.

Y parece ser inadecuada tal exigencia al salvavidas de una piscina porque, aunque el conocimiento sobre natación es propio del rol de salvavidas, dicho conocimiento está siendo exigido en un grado superior a aquél que exigido para cualquiera que ocupe dicho rol 
social. Luego, para que un conocimiento pueda reputarse materialmente especial debe distar de aquél exigido para el cumplimiento del rol social a cualquiera que desempeñe dicho cargo tanto por la naturaleza como por el grado.

Es materialmente especial no sólo el conocimiento ajeno al rol social por la naturaleza sobre la cual versa (por ejemplo, el discernimiento de botánica avanzada con respecto de aquél esperado de un mesero) sino además aquél que desborda el grado exigible de tal conocimiento para cualquier persona que desempeñe el rol social (por ejemplo, el caso de un ingeniero mecánico que acaba de inventar una técnica de frenado que nadie más conoce dentro de su gremio).

En palabras de Jakobs: "conocimiento especial es aquel que no corresponde al rol del autor, o aquel basado en un escrúpulo excesivo: esa clase de conocimiento no tiene relevancia en la valoración normativa y por ende social de la conducta" (2004, p. 348). Esto implica que, para que un conocimiento pueda derivarse de una determinada posición jurídica, y, consecuentemente, sea exigible a cualquiera que desempeñe tal posición, se requieren dos aspectos atendiendo a la materia: primero, que por su naturaleza esté vinculado en forma directa con el normal ejercicio de la posición que ocupa el autor; y segundo, que esté dado en el grado exigible a cualquiera que ocupa tal posición'. Inversamente, para que un conocimiento sea especial, materialmente hablando, se necesita que por su objeto no haga parte de aquél comprendido por la posición jurídica del autor o que, haciéndolo, esté dado en un grado superior al comúnmente exigible para el que desempeña tal cargo o posición. Por ello, "los conocimientos especiales tienen importancia solo en los casos en que pertenecen al rol y en el promedio exigido dentro del rol específico en que se desarrolla la conducta" (Ruiz, 2011, p. 192). Esta es, sin embargo, una caracterización de la materia que es contradictoria si es aplicada al presente trabajo, pues, como se verá más adelante, el conocimiento especial no puede - por definición- pertenecer al rol ni mucho menos hacerlo en el promedio exigido. Esto riñe con la definición misma de especialidad en sentido material, pero como idea general expresa en el fondo el mismo sentido que aquí.

\section{En cuanto a la forma: especial es aquél conocimiento adquirido mediante el ejercicio de un rol social diferente.}

Existen tres formas a partir de las cuales el conocimiento puede originarse. La primera, es aquella en la cual él está ligado al ejercicio 
del mismo rol social; la segunda, lo vincula al conocimiento por azar. Y la tercera, lo liga al ejercicio de otro rol social. A continuación se estudian las tres en aras de determinar cuál es su incidencia a la hora de evaluar la especialidad de un conocimiento.

- Conocimientos adquiridos mediante el ejercicio del mismo rol.

Además de ser materialmente especial, un conocimiento debe tener tal atributo para que ello pueda predicarse también de la forma como el autor lo obtuvo; parece ser que sólo conocimientos que no hayan sido adquiridos mediante el uso del rol social sub examine podrán reputarse de verdad especiales. Hay, pues, otro aspecto de la especialidad además del material: es conocimiento formalmente especial, aquél que no es fruto del ejercicio directo del mismo rol social, esto es, el que desempeña el autor al momento de cometer la conducta que está siendo enjuiciada.

Supóngase el siguiente caso: en el restaurante 'La mosca farsante' el mesero Daniel lleva una ensalada con nueces al comensal Jairo, quien al momento de solicitarla no recordó que era mortalmente alérgico a las nueces. En un primer supuesto, Daniel es estudiante de medicina haciendo su año rural en un hospital en donde alguna vez trataron a Jairo. En dicha ocasión, tuvo la oportunidad de conocer la historia clínica del sujeto y percatarse de su alergia a tal alimento; sin embargo, ahora que Jairo ha solicitado un veneno potencial para su salud, Daniel sirve la ensalada sin recordarle su condición.

En un segundo supuesto, Daniel es mesero tiempo completo y al momento de hacer el pedido, Jairo ordena la ensalada de la casa. Mientras Daniel lleva la comida al comensal, es advertido por la esposa de Jairo de su mortal alergia a las nueces; éste omite la recomendación y cumple las órdenes de Jairo sin advertirle sobre el contenido de la ensalada. El comensal muere a causa de su alergia.

Como se puede apreciar, en esta ocasión la diferencia básica entre ambos casos es la forma en la cual Daniel adquirió el conocimiento. Dejando a un lado las circunstancias triviales de la hipótesis propuesta, parece ser que lo relevante es que en el primer evento, el conocimiento no sólo es materialmente ajeno al rol del mesero sino que, además, su actividad de mesero no tuvo incidencia alguna en la forma en la que adquirió el conocimiento. En este sentido, el rol social es por completo ajeno al conocimiento, tanto por la materia como por la forma en que este ingresó. No obstante, no puede predicarse lo mismo 
del segundo caso, pues aun cuando ningún empleado de restaurante tendría por qué verificar las alergias de los comensales a los que atiende, no puede negarse que el conocimiento adquirido fue producto directo y exclusivo del ejercicio del rol social que desempeñaba.

De hecho, aunque no se tenga una posición decantada sobre el papel que deben jugar este tipo de conocimientos en el juicio de responsabilidad del autor, parece al menos curioso que pudiera asimilarse ambos casos y así exorcizar los conocimientos que el autor posee de toda exigencia de aplicación, por la sola condición de ser materialmente especial (incluso cuando dicho rol social hubiese sido la razón crucial por la cual dicho conocimiento se produjo en el autor). Tal concepción haría del rol social ciego con respecto a sí mismo, pues desconocer la incidencia que tienen los conocimientos materialmente especiales cuando son fruto del ejercicio del propio rol social es transformar al que lo ejerce en un autómata para el cual conocimiento especial sería toda forma de conocimiento nuevo.

No parece haber mayor problema en aceptar que cuando un rol social es la fuente formal ${ }^{10}$ de la adquisición del conocimiento, éste no puede reputarse especial con respecto al mismo rol social. Por el contrario, toda vez que por el propio ejercicio de un rol social se obtenga un conocimiento determinado no contenido en el conjunto de exigencias que el Estado imponía a todo el que ejerciera dicho rol, tal saber jamás podrá ser especial y ha de ser tenido en cuenta por el autor como formalmente perteneciente al mismo; en este sentido, podría hablarse de una especie de inclusión material a partir de la forma en la que fue adquirido, aunque consecuente con lo dicho esto traería sólo confusión, razón por la cual es preferible metodológicamente no ahondar sobre esta relación en estos momentos. Así las cosas, podría establecerse que una vez el conocimiento emana del ejercicio de un rol social, el mismo habrá de ser aplicado en el ejercicio futuro de dicho rol social aunque pueda ser especial con respecto a otros roles sociales. Sin embargo, más polémica genera el trato que deba dárseles a los conocimientos en los cuales no media ninguna especial posición, ningún rol social, es decir, aquellos llamados por azar.

\section{Conocimientos adquiridos sin que medie ningún rol social.}

Antes de abordar el segundo escenario, debe precisarse que significa sin que medie ningún rol social. Aunque es absolutamente coincidente con el objeto de estudio, por cuestiones de extensión y 
enfoque es imposible que se aborde con profundidad la siguiente pregunta: ¿es la figura del buen ciudadano un rol social? La respuesta, en breve, es sí y no: sí es un rol social, pero no es uno como los demás. Por el contrario, la figura del buen ciudadano resulta ser el sustrato, el fundamento, de todos los demás roles. El rol social de buen ciudadano es el presupuesto para que pueda desarrollarse la teoría de los roles sociales. Así cabría diferenciar entre dos tipos de rol social: uno general, que es el fundamento de la expectativa general del Estado de que sus integrantes se comportarán conforme a las normas legítimamente dictadas; y otros especiales o particulares, que son los empleados con frecuencia: conductor, ingeniero, salvavidas, etc.

Por cuestiones de claridad -que no de fondo-, en adelante rol social ha de entenderse como rol social particular en el segundo sentido aquí expresado. Sólo cuando se mencione una diferencia expresa habrá de tenerse al buen ciudadano como persona que cumple un rol social, aunque en efecto lo sea. Por lo tanto, cuando se mencione ningún rol social se afirma que aunque subsiste claramente el rol de buen ciudadano (sea cual fuere su definición) no media ninguno de los roles especiales o particulares que tal buen ciudadano puede -jademás!- desempeñar.

Normas sociales que prohíban el homicidio, el hurto, etc. así como las que dicten que hay que acatar las directivas legítimamente emitidas por una autoridad competente, no son más que normas propias de la estructura misma del Estado de Derecho, y en tanto tales no son predicables de ningún rol social en particular. Para efectos de la exposición, el ser buen ciudadano no es un rol social particular, es el sustrato que da sentido a todo deber en un Estado de Derecho, y, con ello, a la existencia misma de la discriminación basada en roles sociales (particulares).

Bien lo dice Jakobs (1996): "las capacidades llevadas diariamente a la práctica deben ser siempre aplicadas; conocimientos especiales sólo puede haber en los roles divisibles" (p. 281); por ello, entonces, no es adecuado hablar de conocimientos especiales distintos a los del rol de ciudadano común con el fin de incluir dentro de ellos los conocimientos de medicina, ingeniería, botánica, etc. Por el contrario, el conocimiento de medicina sólo puede ser especial con respecto a aquél propio del estado del arte para los médicos, y así para cada rol: sin rol social, no hay conocimientos especiales (también, Jakobs, 2011, p. 284) ${ }^{11}$. 
Ahora bien, en la actualidad hay quienes sostienen que el azar no juega ningún papel a la hora de evaluar los conocimientos poseídos por el sujeto activo. En efecto, se afirma que a los saberes procedentes de una posición jurídica pertenecen también los que provienen del azar (Paredes, 2005, p. 262). Más aún, se dice que los conocimientos pueden ser modificados "simplemente por el azar, esto es, por el mero hecho de ocupar dicha posición [jurídica]" (Paredes, 2005, p. 263) sin que esto afecte en nada el criterio según el cual se mide la exigibilidad de su implementación. En este sentido, Hirsch afirma que "son conocimientos procedentes del azar los relativos a veneno del camarero que estudiaba Biología (conocimientos derivados de otras posiciones jurídicas desempeñadas por el mismo sujeto), los que una persona adquiere por una conversación en tren (conocimientos suscitados por acontecimientos casuales) (...)" (ver Hirsch, 1998, p. 89), equiparando conocimientos que -por su forma de adquisición- son radicalmente diferentes.

No obstante, también se ha dicho que no pueden ser equiparados conocimientos que por su forma de adquisición presuponen una especial posición jurídica, con otros que son comunes a todas las personas en cuanto no conllevan tal especialidad (García, 2004, p. 157). De hecho, para cierto sector doctrinal, los conocimientos especiales no sólo son especiales en cuanto a la materia sobre la cual versan sino también por la forma como son adquiridos por el sujeto activo (Caro, 2006, p. 235). Para que un conocimiento pueda ser verdaderamente especial se requiere -además de lo expuesto anteriormente- que sea accesible sólo por vías especiales. La pregunta a formular en casos de conocimientos denominados por azar es ¿qué tienen de especial los conocimientos accesibles al común de las personas, independientemente del rol social que desempeñen? La respuesta, o bien puede estar dada por un cambio de modelo, o bien ha de ser como la que aquí se expone.

Mir (2011) afirma que los conocimientos especiales suelen ser "el fruto de un aprendizaje particularmente intenso" (p. 300). Así -aunque basado en un modelo diferente al aquí propuesto- explica: "para la averiguación de si hubo infracción de la norma de cuidado deberá preguntarse qué hubiera hecho el hombre diligente en la misma situación del cirujano, es decir contando con el dato de su excepcional preparación" (Mir, 2011, p. 301). Esto sugiere que dentro de la misma concepción de la especialidad del conocimiento, se encuentra el recurso a un origen de tal conocimiento, uno que no es accesible a la generalidad de las personas. 
Habiendo ya establecido que no es una vía especial aquella propia del ejercicio del rol en cuestión (primer escenario estudiado), además debe completarse diciendo que tampoco es una vía especial la accesible al común de las personas independientemente del rol social que ocupen. Como suele suceder con opuestos relativos como frío-caliente, alto-bajo, rápido-lento, no hay especial u ordinario sin tener como referente aquello a partir de lo cual éstas han de determinarse: para el presente modelo, el rol social. Una vez se constata que el rol social (más concretamente: el conjunto de expectativas contenidas en el rol social) es el parámetro a partir del cual ha de apreciarse cuándo un conocimiento es especial, no tiene sentido predicar tal cualidad de aquellos conocimientos que son accesibles sin respecto alguno de dicha figura.

Es ésta la razón fundamental por la cual debe abogarse por una teoría de la especialidad formal: especialidad y ordinariedad son términos relativos, que (como tales) deben estar referidos siempre a un parámetro. En el presente caso, se ha establecido la figura del rol social como el baremo a partir del cual puede determinarse cuándo un conocimiento es especial y cuándo no. Como no hay rol social en abstracto, tampoco hay especialidad en abstracto: ésta deberá determinarse en cada caso conforme al conjunto de expectativas que el Estado impone a tal o cual función que una persona desempeñe en la sociedad. Si el conocimiento no puede relativizarse a uno o varios roles sociales, porque es completamente ajeno a un rol social en particular, no hay un parámetro real a partir del cual pueda establecerse su especialidad (como tampoco sería posible para ninguna otra teoría si antes no se constata la pauta a partir de la cual evaluar dicha cualidad, llámese buen ciudadano, hombre prudente, etc.). Si se ha dicho que sólo los conocimientos especiales deben ser excluidos de la exigencia de aplicación, no hay una razón real por la cual los conocimientos por azar deban ser desechados, pues estos no son (por definición) especiales.

Fuera de esto, cabe notar que no pueden reducirse los casos de conocimientos por azar a aquellos abarcados por la especialidad material, que se predica del conjunto de conocimientos que no están incluidos en las exigencias que el Estado impone a un determinado rol social. Así las cosas, los conocimientos por azar deben ser siempre materialmente especiales. Pero, como por su forma no se refieren a ningún rol social en especial, pues le son accesibles al común de las personas independientemente de su "posición en el tráfico jurídico" 
(García, 2004, p. 162), no cumplen con el requisito de especialidad en sentido formal.

La equiparación hecha por Hirsch entre conocimientos que presuponen un estudio riguroso sobre el tema y aquellos que lo único que conllevan es una azarosa circunstancia en la cual se ve envuelto el sujeto activo, no parece ser adecuada ni mucho menos útil para estos efectos. Lo cierto, es que los conocimientos adquiridos por suerte podrán ser materialmente especiales pero no lo son en cuanto a la forma y, por ende, no quedan comprometidos con las consideraciones aquí adelantadas; tal es el caso de quien, a punto de iniciar una pelea callejera, es advertido de la condición de hemofílico de su oponente. Dicho conocimiento no puede tildarse de especial, por lo tanto debe excluirse de las consideraciones que aquí se pretenden esgrimir; tampoco es un caso de conocimientos especiales el del médico con respecto al que posee cualquier otro ciudadano, ni casos similares.

\section{Conocimientos adquiridos mediante el ejercicio de otro rol social.}

Con arreglo a una teoría de la división funcional de la sociedad, los conocimientos que son materialmente ajenos al rol social que se desempeña y a su vez emanan de uno diferente, solo han de ser exigibles cuando ambos roles sociales sean ejercidos en un mismo y único momento. En efecto, suele suceder que en el discurrir de la vida en sociedad una persona ejerza dos o más roles sociales en distintos momentos, lo cual no quiere decir que ella tenga que atender a las exigencias de los mismos en todo momento (Ruiz, 2011, p. 195). Por el contrario, las exigencias del Ordenamiento se encuentran doblemente demarcadas: primero, por el ámbito de responsabilidad que pertenece al rol social (aquello que ha sido abordado bajo el rótulo de materia); pero segundo, también por el tiempo en el cual se tenga responsabilidad sobre tal ámbito (es decir, el tiempo en el que se ejerza, o deba ejercerse el mismo).

En consecuencia, una vez cese el ejercicio del rol social porque no se lleva a cabo y porque no se debe ejercer, acaban también las expectativas que el mismo conlleva; $y$, con ello, termina la exigencia de aplicar conocimientos que son propios a tal rol social. Esto implica que en el ejercicio de un rol social, tampoco deba ser exigida la aplicación de conocimientos que pertenecen material y formalmente a otro rol social particular (que, se repite, no es desempeñado para tal momento). 
Las razones arriba esgrimidas arrojan una señera conclusión: solo los conocimientos originados en el ejercicio de un rol social diferente al que desempeñaba el autor al momento de desplegar la conducta presuntamente objeto de reproche, son formalmente especiales con respecto al mismo. Dicho de otra manera: solo los conocimientos originados por el ejercicio de otro rol social son formalmente especiales, cuando él cesa en su ejercicio.

Esta es otra forma, para volver al ejemplo arriba propuesto, en la que puede explicarse la diferencia de trato que merece el saber que Jairo es alérgico a las nueces por ser estudiante de medicina, frente al mismo saber cuándo se origina en una advertencia hecha por la esposa al mesero que sirve la ensalada. En el primer caso, el hecho de que Daniel sea mesero en nada influye sobre el conocimiento que tiene de la alergia de Jairo; por el contrario, éste subsiste por fuera de su rol de mesero. En el segundo, el hecho de que Daniel sea el mesero de Jairo es la razón crucial por la cual es advertido de su condición, siendo el depositario de la expectativa legítima de la esposa de que una vez advertido sobre su condición mande a retirar las nueces de la ensalada. En el primer caso, Daniel omite una acción de salvamento generalmente dispuesta por el deber de solidaridad que tienen las personas entre sí en una sociedad, independientemente del rol que se encuentren desempeñando; en el otro, Daniel defrauda las expectativas particulares que legítimamente la esposa - o cualquier otra persona- deposita en la posición que ocupa frente al comensal alérgico.

Así las cosas, los únicos conocimientos que pueden ostentar la condición de especialidad formal son aquellos que son el fruto del ejercicio de un rol social diferente -ténganse en cuenta las consideraciones en torno a la diferencia entre roles sociales particulares y generales, anteriormente desarrolladas- al que se detenta al momento desplegar la conducta enjuiciada.

\section{Definición general de conocimiento especial.}

En resumen, los conocimientos de los que se ocupa el presente estudio son los formal y materialmente calificables de especiales. Son materialmente especiales, cuando no están incluidos dentro del conjunto de expectativas que un Estado impone a una determinada posición jurídica dentro de la sociedad; o cuando, pese a estar incluidos dentro de ella, se presentan en un grado superior al 
promedio exigible para ocuparla ${ }^{12}$. Es un conocimiento promedio para ocupar una posición jurídica dentro de la sociedad, aquél cuya ausencia generaría un reproche penal y fundamentaría un delito imprudente. La ausencia de un conocimiento materialmente especial nunca generará el reproche de un delito imprudente; valga decir: "en el delito imprudente la no aplicación del saber especial o aptitud especial a consecuencia de una falta de atención sólo permite la imputación del resultado lesivo cuando compete el deber de aplicarlo" (Choclán, 1998, p. 29).

Son formalmente especiales cuando: de un lado, dicho conocimiento no nace a partir del ejercicio del mismo rol social; y, de otro, si no fueron adquiridos por vías accesibles al común de las personas independientemente del rol social que desempeñen. En consecuencia, son formalmente especiales solo los conocimientos que son fruto del ejercicio de un rol social distinto al que se ejerce al momento de desplegar la conducta evaluada.

Así las cosas, saber que el conductor de un tren está borracho porque se escuchó a alguien decirlo, tener conocimiento de que se avecina una tormenta eléctrica porque se percató de que el cielo está nublado, estar al corriente de que un avión va a explotar porque se vio a alguien poner una bomba, etc., no son ni lo uno ni lo otro. En cambio, en principio, conocer de una técnica médica novedosa porque se dirige un grupo de investigación, tener conciencia del veneno contenido en una ensalada porque se estudia botánica, etc., hacen parte del objeto de estudio de esta materia. En últimas, si un conocimiento no es material y formalmente especial, no puede ser considerado sino como "mera subjetividad que no se está en obligación de conseguir ni mucho menos de mantener" (Jakobs, 1998, p. 48).

Por lo dicho, se entiende que conocimiento especial es aquel que no perteneciendo a la posición que ostenta el autor al momento de actuar, o perteneciendo en un grado superior al común, es adquirido por vías que no emanan del ejercicio del mismo rol social ni son accesibles para el común de las personas sino que requieren, a su vez, de una posición jurídica en la cual el autor tenga alto grado de especialización en esa materia. Para que sea especial se requiere: que no sea connatural a su posición jurídica o que, siéndolo, esté dado en un grado superior al estándar usado para determinar la responsabilidad penal en caso de su ausencia; y además, que sea adquirido por vías tales que sólo una persona que ocupe un rol social distinto al que desempeña el autor al momento de la conducta 
le fuera accesible. Los dos primeros requisitos, dados de forma alternativa, suponen especialidad según la materia; el último, versa sobre la especialidad en cuanto a la forma de adquisición.

\section{Conocimientos especiales y rol social}

Tal y como lo explica la profesora Ruiz (2011), la importancia de valorar los conocimientos especiales -sólo en la medida en que se encuentren directamente relacionados con el rol que se cumpleobedece a que contribuye a la constitución del injusto, pues no puede haber tipicidad sin relevancia social de la conducta (p. 190). Así, agrega, "los denominados "conocimientos especiales" tienen importancia sólo en los casos en que pertenecen al rol y en el promedio exigido dentro del rol específico en que se desarrolla la conducta" (2011, p. 191).

Pese a estar de acuerdo con la conclusión -y fundamentos- el camino adoptado aquí es sustancialmente diferente pues parte de una definición de conocimientos especiales distinta. En efecto, aun cuando de manera general se esté de acuerdo en que "la existencia de conocimientos especiales diferentes de los que se deben tener en el rol que se desempeña en un momento determinado no tiene incidencia alguna en la graduación del delito imprudente" (Ruiz, 2011, p. 197), es menester realizar algunas precisiones importantes con base en lo expresado en el acápite anterior.

Lo primero, es que para hablar de un conocimiento especial diferente al rol puede resultar redundante. Ya se ha establecido que para que un conocimiento pueda tildarse de especial, es menester que lo sea tanto formal como materialmente; también se ha dicho que conocimientos especiales que "pertenecen al rol y en el promedio exigido (...)" (en los términos de la profesora Ruiz) no son materialmente especiales en los términos aquí propuestos. Decir que al médico ginecoobstetra le es exigible un conocimiento especial de una técnica usual para realizar una histerectomía en el promedio exigido para los demás médicos ginecoobstetras, no es hablar de conocimientos especiales. La violación del deber objetivo de cuidado de aquél que no aplica lo que debería saber para ocupar su rol de médico es evidente. Es claro, entonces, que no es acorde hablar de conocimientos especiales que pertenecen al rol y en el promedio exigido; si es un conocimiento especial, entonces no pertenece al rol social o no lo hace en el promedio exigido. 
Además, tampoco parece consistente afirmar que cuando los conocimientos especiales pertenecen al rol y en el promedio exigido, ésta "[sea] la única manera en que pueden tener incidencia o importancia en la graduación del delito imprudente" (Ruiz, 2011, p. 192). La razón: no sólo cuando pertenecen al rol en el promedio, pueden ser evaluados los conocimientos en la graduación del delito imprudente. De hecho, esto solo atañe al aspecto material de la especialidad del conocimiento, pero ya se ha dicho que para que un conocimiento sea especial requiere además de un aspecto formal. Por lo tanto, además de los casos mencionados por la citada profesora, un conocimiento puede (y debe) incluirse dentro de la valoración hecha para determinar la violación al deber objetivo de cuidado si fue adquirido de forma no especial. Luego, si el mesero sabe que la ensalada está envenenada porque escuchó a dos comensales hablar al respecto, $y$, sin embargo, la sirve a otro comensal, crea un riesgo jurídicamente desaprobado al violar su deber objetivo de cuidado toda vez que el conocimiento fue adquirido de manera ordinaria, vale decir que no medió ningún rol especial en la forma de adquisición del conocimiento. Es decir, aunque el conocimiento de botánica es materialmente especial con respecto al rol de mesero, formalmente no lo es pues para su adquisición no medió una especial posición más allá de haber escuchado la conversación de dos comensales, algo no especialmente raro para un mesero.

Fuera de esto, se está de acuerdo con la profesora Ruiz en que no puede negarse que el Derecho penal es una expresión de sentido que es vinculante por el significado en un contexto social, no siendo relevante según la opinión de cada individuo. Es por ello que no se pueden tener en cuenta los conocimientos individuales en roles diversos a los que se juzgan, porque esa valoración se hace desde una perspectiva social que en materia penal se encuentra en los criterios de la imputación objetiva del comportamiento (Ruiz, 2011, p. 195).

\section{Posiciones de garante.}

Todo esto nos lleva a una pregunta inevitable: ¿puede un conocimiento especial fundar una posición de garante? Sobre la cuestión un par de ejemplos reformulados por el propio Jakobs han resonado con particular polémica:

Un estudiante avanzado de Biología, que se emplea durante las vacaciones como camarero, gracias al saber adquirido en sus estudios reconoce en una ensalada, lista para ser servida, una planta 
muy venenosa que se parece de manera muy engañosa a una clase de perejil que también contiene la misma; impasible, sirve la ensalada (1998, p. 280); y un ingeniero automotriz, especialista en frenos, conduce un auto alquilado y concluye a partir de algunos indicios reconocibles sólo para pocos especialistas, que en breve (aunque no todavía durante su travesía) se producirá un desperfecto en los frenos; el ingeniero devuelve el automóvil sin dar aviso del peligro. El siguiente locatario del automóvil sufre un accidente (Jakobs, 2011, p. 280; Kaufmann, 1976, p. 281).

En la doctrina, son abundantes las posiciones que harían responsable al mesero en caso de que el comensal sufra de una lesión. De hecho, en situaciones en las cuales no hay lesión alguna dado que el comensal no comió la ensalada -porque se percató de la planta venenosa, o porque perdió el apetito, entre otras varias razones similares-, gran polémica genera la posibilidad de sancionar mediante una tentativa (Sacher, 1998). Igualmente, también es dable aunque menos frecuente encontrar en la doctrina posturas que harían al ingeniero automotriz responsable de las lesiones del siguiente conductor [sobre si ésta deba ser dolosa o culposa, por acción o por omisión, ver, por todos, Jakobs, 2011, p. 280, con cita de Greco].

No obstante, explica Jakobs, antes de tomar una postura sobre el particular -en escenarios de daño o de peligro para los bienes jurídicos vida o integridad personal del comensal o del conductor, da igual- es indispensable preguntarse por la génesis de la obligación del mesero frente al comensal o del ingeniero sobre el siguiente conductor. Esto es, indagar si entre ellos existía una posición de garan$\mathrm{te}^{13}$ predicable del primero con respecto al segundo. De constatarse que existía una posición de garante, el conocimiento no podrá seguir siendo materialmente especial pues en tales casos debe incluirse dentro del conjunto de exigencias que el Estado ordinariamente impone al sujeto ${ }^{14}$.

Debe recordarse que según la definición aquí propuesta la especialidad de los conocimientos viene dada -materialmenteporque se refiere a un objeto del que el autor no tiene que ocuparse o, formulado con más precisión jurídica, que está fuera de los riesgos que debe administrar como garante (Jakobs, 2011, 281). Por ello, no solo el camarero no tiene que examinar con detenimiento la ensalada, o el ingeniero el automóvil, sino que incluso luego de que ha identificado la planta o la falla de los frenos, "el curso posterior 
puede seguir siendo indiferente para el autor" (Jakobs, 2011, p. 282). En igual sentido, al abordar el ejemplo del camarero, un sector de la doctrina suele argumentar que "al respecto, cabe decir que el camarero no tiene el deber de controlar el riesgo -los camareros no son responsables del control de salubridad de los ingredientes de los alimentos que sirven- y por ello no puede imputarse al sujeto no haberlo controlado" (Piña, 2002, p. 55).

Lo cierto es que las personas nunca saben exclusivamente lo que les toca conocer para desempeñar adecuadamente un rol en la sociedad. Por el contrario, su conocimiento desborda -bien sea por la materia o por el grado- lo exigido por el Ordenamiento para el adecuado desempeño de un determinado rol social. La pregunta está en si, dado que una persona conoce más de lo que debería, ésta debería ser responsable penalmente por las consecuencias que pudieron evitarse mediante la aplicación de tal conocimiento. Y la respuesta sólo puede estar dada por una diferenciación entre aquello que sabe y aquello que debe saber; distingo basado en los límites que el propio rol le impone a cualquiera que lo desempeñe en un determinado momento.

En términos de Jakobs: "la pregunta inicial correcta no tiene que dirigirse a los conocimientos de un causante, sino a lo que él tiene que garantizar, (...) no hay ninguna conexión obligatoria entre conocimiento y amplitud del deber" (2011, p. 279). Esto implica que para poder definir la especialidad de un conocimiento, debe antes verificarse la existencia o no de una posición de garante, y no al revés. En términos simples: mientras que la posición de garante impone la obligación de activar los conocimientos especiales, la sola posesión de ellos no genera una posición de garante.

En este punto es indispensable diferenciar entre los deberes generales de cuidado y los deberes especiales de cuidado -o deberes de garante- (Jakobs, 2001). En toda sociedad, cada persona presenta un deber general de cuidado con respecto a los demás. Esto, porque en toda sociedad moderna el riesgo es parte inherente de la vida diaria (Silva, 2009) y él, muchas veces originado por el comportamiento de los conciudadanos, frecuentemente se encuentra regulado bien sea por normas penales, jurídicas o sociales (sin que éstas sean categorías excluyentes). Actividades como las de conducir, salir de cacería y muchas otras similares, suponen cierto riesgo para los demás, razón por la cual siempre ha de verificarse un cuidado general -en tanto no va dirigido a favor de una persona en particular- al momento de desplegarlas. Las formas básicas del cuidado general suponen 
la ausencia de comportamientos voluntariamente dirigidos hacia la producción de un daño (o peligro) antijurídico para un bien jurídico ajeno. Así las cosas, infringiría su deber general de cuidado no sólo quien imprudentemente viaja a exceso de velocidad sino, también, quien dolosamente dispara en contra de alguien más.

En estos casos, el deber de cuidado violentado no parece predicarse a favor de ninguna otra persona en particular, sino de la generalidad de las demás personas. Si en tales casos se requiere un deber de cuidado general, mal habría de pedirse un comportamiento que -objetiva o subjetivamente (sea como fuere que se le defina)- suponga un talento especial. Para que pueda exigirse un cuidado general de todos los ciudadanos a favor de la generalidad de las demás personas, deben tenerse como parámetro los comportamientos que son exigibles al promedio en cuanto a la administración de su propio ámbito de competencia; por eso dice Jakobs (2011): "[e]ste cuidar de la seguridad, sin la existencia de un vínculo especial, no forma parte de las tareas de una persona en derecho que administra su propio ámbito, sino más bien del Estado y, por consiguiente, no hay ningún deber de garante respecto de un ciudadano de estas características" (refiriéndose al camarero) (p. 283).

Sin embargo, en ciertos casos, el Estado impone sobre un particular la obligación -esta sí- especial de cuidado a favor de otro particular, de un grupo determinado, o en ciertos casos de un grupo indeterminado, como aquellos en los cuales se verifica una actividad especialmente peligrosa: administración de fuentes de riesgo (Velásquez, 2009, p. 658). En tales eventos, el Estado exige un comportamiento especial para asegurar la ausencia de daño o peligro antijurídico de un bien ajeno. La diferencia notable frente al primer caso de exigencia de comportamientos, es que en el presente ella no parte -ni debe partir- de aquella impartida al promedio de las personas; en tales situaciones, la persona sobre la cual recae el especial deber de cuidado debe hacer todo lo posible para evitar la producción del daño o peligro antijurídico en el bien encargado. Hasta el momento, se ha verificado la posibilidad de exigir la activación de conocimientos especiales para casos en los cuales sólo subsiste un deber general de cuidado; no pueden aplicarse las mismas consideraciones cuando se está frente a una posición de garante, pues ésta supone un deber especial de cuidado.

En el caso del mesero, como en el del conductor, el Estado sólo puede exigir aquello que corresponde a la generalidad de las perso- 
nas frente a las demás: un deber de solidaridad. Así, a lo sumo, el mesero como el conductor, serán responsables de un delito de omisión de socorro -en tanto deber general- contemplado en el artículo 131 del Código Penal colombiano. La omisión en la activación de los conocimientos especiales únicamente puede fundamentar la omisión propia contemplada en tal artículo pues es una manifestación del deber general predicable de toda persona independientemente del rol social que desempeñe para el momento, pues "[1]a persona pública, el ciudadano, es convocado al ejercicio de la función -pequeña y sólo temporaria-: cuidar de la seguridad de un caso particular" (Jakobs, 2011, p. 283). Así las cosas, a menos de que se verifique una especial posición de garante entre el mesero y el comensal, o entre el conductor y el siguiente conductor, sus conocimientos sobre biología e ingeniería automotriz siguen siendo -para todos los efectos- materialmente especiales.

\section{Rol social y conocimiento especial relevante.}

En casos como el del mesero, es fácilmente apreciable que no media ninguna especial posición de garante a la hora de servir la comida de su comensal, como tampoco la tiene el conductor del carro con respecto a los demás que puedan alquilarlo con posterioridad. Pero, sus conocimientos pueden ser aplicables si se constata que no son verdaderamente especiales, algo que deberá mirarse con cuidado, pues, si no se verifica esto, aun cuando no exista posición de garante, deberán ser aplicados.

Es decir, con independencia de que medie una posición de garante o no, si los conocimientos ni siquiera se remontan a la categoría de especiales es claro que deben ser aplicados y que, en ambos casos, habría responsabilidad penal por su omisión. Esto deberá analizarse a la luz de la especialidad no sólo material sino también formal, pues, recuérdese, solo puede predicarse verdadera especialidad -y con ello falta de exigencia en la aplicación- cuando ambas facetas sean verificables en una situación dada.

A primera vista, parecería que aunque el conocimiento sobre la existencia de una planta venenosa en la ensalada, o de una falla en el sistema de frenado de un auto alquilado, son materialmente especiales (pues requieren de conocimientos sobre botánica o sobre ingeniería automotriz, respectivamente) tanto por su naturaleza como por su grado en comparación con aquel que debe saber el mesero y el conductor promedio, formalmente no lo serían. Y no 
serían formalmente especiales, porque el estudiante de botánica se ha enterado de la existencia de la planta venenosa en el plato del comensal precisamente porque le llevaba la ensalada en su condición de mesero. De igual forma, el ingeniero automotor se percató de la existencia de una falla de frenos precisamente porque en su calidad de arrendatario, él se encontraba manejando el carro en cuestión. Luego, aunque fueran conocimientos materialmente especiales, habrían de activarse toda vez que ingresaron a su conciencia a través del rol social desempeñado y gracias a éste.

Ciertamente, parecería que sin la intervención del rol social de mesero, o de conductor, jamás hubieran obtenido los conocimientos en cuestión, a saber: que existía tal planta venenosa en la ensalada que servía, o que el carro que alquiló tenía tal falla en los frenos, ambos tendentes a una afectación casi segura del bien jurídico del comensal o del próximo conductor. No obstante, dejarse llevar por tan seductora forma de constatar la ausencia de especialidad formal sería inadecuado, pues tal argumentación es falaz. Ello es así, porque se ha confundido el tipo de conocimiento relevante para el caso igualando, indistintamente, casos en los cuales el conocimiento fáctico es el relevante a casos en los cuales el conocimiento nomológico es el relevante.

En el discurrir de la vida de cualquier persona, los conocimientos vienendados pordoscategorías: conocimientos sobrela configuración del mundo o sobre las leyes que rigen la forma en la que el mundo está conformado; por supuesto, puede argumentarse que las leyes que rigen la configuración del mundo también hacen parte de la misma, pero tal discusión sería -para efectos del presente acápite, y en general del trabajo- perniciosa. Un ejemplo de los primeros sería aquél en el cual el sobrino codicioso sabe de la existencia de una bomba en el tren que va a abordar su tío; un ejemplo del segundo, es el caso en el cual el mismo sobrino sabe que existe una regla meteorológica según la cual dado el nivel de humedad relativo, la presión atmosférica y la temperatura al momento, se producirá una tormenta eléctrica en una región por la que pasa el avión de su tío justamente en el momento en el cual lo hace.

En la mayoría de los casos, ambos tipos de conocimientos son indistintamente relevantes a la hora del juicio de responsabilidad. Esto, porque a menudo la diferencia entre ambos conocimientos es imposible, y casi siempre se puede llegar a un punto en el que ambos confluyan. Así, puede argumentarse que el saber nomológico de la 
probable producción de la tormenta por la aplicación de una ley meteorológica parte del conocimiento fáctico de las circunstancias que dan origen a la aplicación de tal ley, y sin el cual jamás habría podido predecir el resultado.

Esto parece ocurrir en los ejemplos propuestos por Jakobs. El mesero sólo puede identificar a la planta como venenosa porque, previamente, ha notado que presenta tales y cuales características (en cuanto a la regla: siempre que una planta tenga las características $x, y, z$ es venenosa). Igualmente, el conductor sólo ha podido identificar la falla en los frenos una vez constató ciertas evidencias (en cuanto a la regla: siempre que en el carro se aprecie $x, y, z$ los frenos van a fallar). A pesar de esto, en todo caso de conocimientos especiales la relevancia a la hora de establecer la especialidad puede recaer sobre dos tipos de conocimiento que, aunque confluyan en un mismo y único momento a la hora de prever el resultado, son en el fondo distinguibles. Puede haber casos en los cuales la relevancia esté puesta en el conocimiento fáctico, o aquellos en los que el enfoque sea puesto a los conocimientos nomológicos. Con unos ejemplos esto debe quedar más claro.

Hay hipótesis en las cuales la especialidad del conocimiento está dada por una ontología desconocida para el común de las personas. Supóngase que Jaime es hemofílico, pero ni él ni nadie a excepción de José conocen de tal condición. Una noche, mientras ambos festejaban en un bar, Jaime se enfrasca en una riña en la cual uno de sus oponentes le amenaza con una botella de vidrio quebrada. Ante el silencio de José, Jaime muere a causa de una cortada relativamente leve que -por su especial condición- le produjo una hemorragia masiva. En tal caso, lo relevante no es saber que hay una alta probabilidad de causar muerte por hemorragia al hemofílico que es cortado por una botella en una riña; lo relevante es saber la condición de hemofílico del oponente. Lo que todo el mundo desconoce, y hace del conocimiento de José especial, no es una especial ley sino la forma como está configurado el mundo para el momento de los hechos. Lo apreciable es solo saber la condición de Jaime que, en el presente caso, constituye el conocimiento fáctico relevante para el juicio de responsabilidad ${ }^{15}$.

Pero, puede haber casos en los cuales lo trascendental no sea el conocimiento fáctico sino aquél nomológico. Piénsese en un grupo de amigos universitarios que, al percatarse de un olor extraño en la casa, acertadamente concluyen que el calentador de agua está 
emitiendo más monóxido de carbono que de costumbre. Uno de ellos, estudiante de Medicina, sabe que una vez el nivel del gas incrementa al nivel porcentual $x / \mathrm{O}_{2}$, reemplaza el oxígeno en las células impidiendo que éste llegue al cerebro, matando de una manera casi segura a aquél que se quede a respirarlo. A pesar de ello, no dice nada a sus amigos y finge salir a comprar comida por un rato. En este caso, lo relevante no es el conocimiento fáctico de que el nivel de monóxido de carbono ha incrementado considerablemente en la casa debido a una falla en el calentador; por el contrario, lo trascendente para constatar el peligro es la regla que sólo el estudiante de medicina conoce.

De manera análoga, en el caso del mesero como en el del ingeniero, los conocimientos relevantes no son los fácticos sino los nomológicos. Saber que la planta en cuestión hace parte del plato es un conocimiento fáctico que en nada se diferencia de aquél que obtendría cualquier otro mesero que echara un vistazo a lo que está a punto de servir. No obstante, lo apreciable es saber que es una planta venenosa, y para eso hace falta el conocimiento nomológico que lleva a concluir esto. Así, aunque sea cierto que el discernimiento fáctico es común a todos los que desempeñen el rol de mesero, o el de conductor bajo tales condiciones (al menos si son medianamente atentos), éste es totalmente superfluo si no se cuenta antes con el conocimiento nomológico que permite predecir el resultado relevante. No parece ser adecuado que, por tener como base un conocimiento fáctico (adquirible de forma general mediante el ordinario desempeño de un rol social), el conocimiento nomológico (únicamente adquirible mediante un alto grado de especialización en otro rol social) sea excluido de toda consideración.

En los ejemplos reseñados del mesero y del conductor, estos conocimientos nomológicos son genuinamente especiales tanto por la materia como por la forma. Además de que conocimientos de biología e ingeniería automotriz son materialmente ajenos al rol social desempeñado, también lo son formalmente pues en cuanto a conocimientos nomológicos no pudieron ser adquiridos sino mediante una posición de alto grado de especialización en tal área del conocimiento materialmente especial. Luego, en ambos casos queda verificado que el conocimiento es especial en los términos de este trabajo y, como regla general, no debe ser tenido en cuenta a la hora de evaluar una violación al deber objetivo de cuidado. Sin embargo, esto no obsta para que, excepcionalmente, la conclusión sea distinta. 
Ahora bien, es importante aclarar que nada de lo dicho hasta este momento implica que en ningún caso hayan de aplicarse los conocimientos especiales; de hecho, con base en la corriente decantada por Jakobs (2011, p. 270), serían en principio tres los casos excepcionales de exigibilidad de aplicación de conocimientos especiales. El primero, es el que se presenta cuando media una posición de garante del autor frente al sujeto pasivo; en tales casos, "los conocimientos especiales que se tengan en el ejercicio de un rol deben necesariamente ser aplicados" (Ruiz, 2011, p. 196). Es decir, aquél que tenga una especial posición de garante necesariamente debe hacer todo lo posible para evitar la producción de un resultado disvalioso; no se está en el terreno de los modelos normativos de deber de conducta sino que, más bien, parece aplicarse un patrón de evitabilidad individual dado el especial deber que tiene el sujeto activo (para mayor profundidad sobre esta figura en un esquema normativista, ver Jakobs, 2001).

Con respecto a la particular construcción de la posición de garante, parece ser que se ha incurrido en una ambigüedad terminológica: en algunos casos se habla de anulación de especialidad material por la naturaleza de la figura en cuestión; mientras que aquí se alude a la aplicación excepcional de conocimientos especiales. Lo cierto es que en casos de posición de garante los conocimientos del sujeto activo que desbordan lo que ordinariamente debería saber son plenamente relevantes en el juicio de responsabilidad penal. Pero esto se puede deber a dos cuestiones teóricamente excluyentes: o bien porque no son un caso de conocimientos especiales; o, siéndolo, son aplicables de forma excepcional.

Aquí, se ha definido la especialidad material como aquella que atañe a la diferencia del conocimiento con respecto a la naturaleza de aquellos que se esperan de una persona que ocupe cierto rol social $\mathrm{y}$ con respecto al grado exigible para tal conocimiento. Se ha dicho, también, que al mediar una posición de garante, el conocimiento especial queda abarcado por el conjunto de exigencias que el Estado impone a una persona independientemente de su rol social, debido a la naturaleza de la figura en cuestión. Luego, cuando media una posición de garante los conocimientos antes especiales quedan comprendidos por las exigencias del Estado, dada la naturaleza de la figura. Serían especiales en cuanto a la naturaleza del conocimiento, 
pero quedarían abarcados excepcionalmente por la naturaleza de las exigencias del Estado, que en estos casos no tiene en cuenta la especialidad material tal y como ya ha sido descrita.

En este sentido, el conocimiento en cuanto tal sigue siendo especial con respecto a la naturaleza y grado de aquellos ordinariamente exigibles al rol social, pero no se verifica especialidad material en estricto sentido, porque excepcionalmente el Estado los incluye dentro del conjunto de exigencias impuestas a la persona sin importar su rol social. Frente a casos de posición de garante, se está ante "una vinculación especial que excluye total $\mathrm{o}$, al menos, parcialmente la separación de roles" (Jakobs, 2011, p. 285). El problema surge de una consideración antes esgrimida: sin rol social no hay conocimientos especiales. Esto se debe a que si una exigencia no está discriminada por el rol social que la persona desempeña, no hay un parámetro para establecer su especialidad ${ }^{16}$. De cualquier forma, esta exigencia sigue siendo excepcional, razón por la cual es válido afirmar que la posición de garante es un caso en el cual excepcionalmente deben aplicarse los conocimientos que de otro modo serían genuinamente especiales.

El segundo caso expuesto como aplicación excepcional de conocimientos especiales, es el de manipulación en el uso de un conocimiento especial. Como ha quedado establecido, los conocimientos que materialmente son ajenos al rol tanto por su naturaleza como por su grado, siempre que hayan sido adquiridos de forma especial, no generan responsabilidad penal por su omisión. Sin embargo, cuando él es incorporado al plan criminal del individuo, de tal forma en que "manipule esos conocimientos para alterar el curso causal y de esta forma producir un resultado" (Ruiz, 2011, p.196), cobra plena relevancia para el Derecho penal. Tal es el caso citado por la doctrina que, en la hipótesis del mesero, la modifica al punto de que éste retiene el plato de ensalada envenenada para luego servirlo a su enemigo y conseguir su muerte. Al respecto: "[s]i el autor quebranta, a su vez, una separación de roles en sí existente, (...) entonces el conocimiento especial se transforma en un simple conocimiento de una realización típica inminente" (Jakobs, 2011, p. 285). Esto aplica tanto para el delito doloso (sobre ello, Greco citado por Jakobs, 2011, p. 285), como para el culposo en el cual el sujeto activo utiliza sus conocimientos especiales para alcanzar un fin propio, e imprudentemente produce un resultado disvalioso ${ }^{17}$. Distinto es, por supuesto, el caso en el cual -en el ejemplo expuesto- el destinatario original de la ensalada sea su enemigo ${ }^{18}$. 
El tercer y último caso de presunta aplicación de conocimientos especiales es aquel en cuya virtud el sujeto activo es tenido en cuenta para desempeñar un rol social debido a los conocimientos especiales que tiene sobre tal o cual área del conocimiento. En palabras de la profesora Ruiz (2011), en este supuesto se requiere que "la persona haya sido tenido [sic] en cuenta para desempeñar ese rol específico (...) en consideración de esos conocimientos especiales que eran requeridos para ejercer ese rol"; y añade: "salvo que la persona haya sido tenido en cuenta para desempeñar ese rol específico única y exclusivamente en consideración de esos conocimientos especiales que eran requeridos para ejercer ese rol" (p. 197). Sin embargo, parece demasiado restrictivo exigir que la selección del sujeto activo deba estar basada única y exclusivamente en sus conocimientos especiales para que cobren relevancia; de hecho, basta con afirmar que, una vez el sujeto activo sea seleccionado en un cargo para que aplique sus conocimientos especiales sobre la materia, surge una obligación de aplicarlos pues no puede mantenerse una exigencia genérica para aquél que ha sido seleccionado por su especialidad.

Para seguir con el ejemplo propuesto por Jakobs: supóngase que una vez el mesero omite informar al comensal acerca de la planta venenosa y éste muere, los dueños del restaurante le piden a un compañero de su clase que empiece a trabajar inmediatamente y que esté especialmente atento al contenido de las ensaladas para evitar infortunios como ese en un futuro. En el caso de percatarse de una planta envenenada en otra ensalada, este nuevo mesero no puede desconocer que ha sido contratado no por sus excepcionales calidades de mesero sino por ser estudiante de biología, capaz de reconocer tal evento.

De cualquier forma, no es del todo claro que este ejemplo propuesto por el autor alemán como aplicación excepcional de conocimientos especiales se acomode a lo que aquí se ha entendido en relación con la especialidad desde una perspectiva material; es que, en definitiva, no parece ser coherente que una vez alguien es contratado precisamente porque posee un conocimiento determinado el mismo siga siendo especial con respecto al rol social a ejercer.

Por el contrario, es evidente que el conocimiento especial ha sido incluido dentro del conjunto de requisitos previstos para desempeñar el rol en cuestión, por lo cual no hay razón alguna para tildarlo como tal. Entonces, aun cuando en abstracto sea válido decir que es un caso de aplicación de conocimientos especiales, de acuerdo 
con la definición propuesta tal no sería un caso de conocimiento materialmente especial. Aun cuando la conclusión sea la misma -v.gr., que debe aplicar dicho conocimiento - la forma como se llega a ella es distinta.

\section{Conclusiones}

Con este estudio se ha querido defender la vigencia y utilidad de la teoría de los roles sociales como parámetro a partir del cual ha de definirse cuándo un conocimiento es especial y cuándo no, con el fin claro de establecer cuáles conocimientos que el autor posee cobran relevancia penal y bajo qué escenarios han de ser activados. Para lograr este cometido, antes hubo de recorrerse un largo trayecto que partió de la ubicación sistemática de esta problemática dentro de la teoría material del delito.

A través de la historia, el tema ha sido abordado prácticamente desde todas las sedes posibles. No obstante, recientemente puede constatarse una tendencia en la doctrina mayoritaria por abandonar la diferencia ontológica entre el tipo objetivo y el tipo subjetivo, y, en su lugar, ubicar la problemática en torno a los conocimientos especiales en categorías normativas como el riesgo jurídicamente desaprobado o el deber objetivo de cuidado. A diferencia de la clásica división entre la parte objetiva y subjetiva del tipo, el marco general de la imputación objetiva permite abordar la cuestión de los conocimientos especiales de una forma más amplia, pues no se encuentra atada a las categorías ontológicas tradicionales, pero a su vez muy precisa, pues invita a buscar una serie de criterios normativos que permitan delinear con claridad los límites a la exigencia jurídica en su activación.

Es así como dentro del marco normativo de la imputación objetiva, la teoría de los roles sociales, con planteamientos que no son radicalmente diferentes a los ya aceptados por la doctrina mayoritaria, pero con un número significativamente reducido de seguidores, ofrece el terreno fértil sobre el cual se puede cultivar una definición novedosa de especialidad que ubique los roles (o posiciones) que una persona desempeña en la sociedad como paradigma para establecer claramente los límites de la exigencia jurídica en cuanto a activación de conocimientos se refiere.

Siendo ello así, debe tomarse por conocimiento especial aquél que distando del ordinariamente esperado para el adecuado des- 
empeño de un rol social bien sea por su naturaleza o por el grado en el cual se presenta, sea accesible únicamente por vías que supongan el ejercicio de otro rol social particular. Únicamente de este modo se da cuenta de una diferencia trascendental a la hora de estudiar la relevancia de un conocimiento para la determinación del deber de cuidado: para que un conocimiento sea excluido de la exigencia general de su activación, éste debe ser tanto material como formalmente especial.

Sólo mediante una definición que contenga ambos aspectos pueden sortearse de forma adecuada las paradojas aparentes que surgen de casos como los conocimientos por azar, o aquellos que son fruto del ejercicio directo del rol social sub examine. De igual forma, sólo con dicha definición en mente puede entenderse por qué no puede haber conocimiento especial sin rol social y por qué, como regla general, no debe exigirse la aplicación de ningún conocimiento especial en el ejercicio de un rol social.

Una definición basada en la especialidad formal y material a partir de la teoría normativa de los roles sociales permite, además, dar una santa sepultura a las inconsistencias que son encontradas en la doctrina con respecto a posiciones de garantes, tipos de conocimiento relevante y casos de aplicación excepcional de conocimientos genuinamente especiales. Cada uno de estos aspectos fue abordado en detalle, con lo cual quedó decantada la solución práctica que una definición como la aquí propuesta, y en general como aquella que parte de la teoría aquí defendida, aporta al delicado proceso de alinderar el terreno de lo jurídicamente exigible sin irrespetar el fuero de lo que a cada individuo le es dado decidir en la libre configuración de su personalidad.

Hace más de dos siglos W. Hazlitt pronunció una de las frases más bellas sobre la condición humana. Según él, "el hombre es el único animal que ríe y llora, porque es el único animal que se deja afectar por la diferencia entre lo que las cosas son y lo que deben ser". Lo que parece innegable en las relaciones sociales es que el hombre tiene ante todo una recalcitrante necesidad de ajustar su comportamiento, y el de los demás, conforme a patrones de conducta idealmente definidos. El cómo ha de ser satisfecha esta necesidad, es uno de los interrogantes más oscuros a los cuales debe enfrentarse el Derecho en general. Nuestra jurisprudencia constitucional nos muestra la importancia que tiene la configuración social como fundamento y límite de la valoración jurídica; que el papel del Derecho no es 
moldear la ontología social a partir de criterios normativos estrictos, sino sentar las garantías para que ella muestre al Ordenamiento cuáles prácticas considera reprochables, cuáles conductas han de ser sancionadas.

El problema con la aceptación de la posibilidad jurídica de exigir la activación de conocimientos (verdaderamente) especiales en el proceso penal, es que en aras de salvaguardar la protección de bienes jurídicos, se atenta en contra de la división funcional de la responsabilidad estructurada a partir del reconocimiento de ámbitos de competencia individuales. En el fondo, la cuestión es que parte de una melancólica idea de una sociedad sin accidentes o peligros indeseados para los bienes jurídicos de sus integrantes, en la cual el ser es el deber ser. Esto no va y no puede suceder; sin embargo, necesitamos buscarla. Pero no así, no a cualquier costa.

\section{Notas}

1 Mal podría afirmarse que todo el que cree en el injusto personal como categoría autónoma en la teoría del delito, automáticamente asume que la antijuridicidad es ratio essendi de la tipicidad. Por el contrario, teorías como la de los elementos negativos del tipo o similares son aún hoy muy cuestionada por parte de seguidores de la teoría del injusto personal.

2 Se incluyen aquí los que abogan por figuras como el tipo global, elementos negativos del tipo, función valorativa del tipo, junto con todas las posturas que hacen de la antijuridicidad una ratio essendi de la tipicidad.

3 Quienes dan fe de la predominancia de tal figura durante la segunda mitad del siglo pasado en la doctrina alemana; igualmente, puede verse la STS 18-10-1979 (A. 3737) y 16-6-1987 (A. 4955) que caracterizan una corriente sumamente decantada en el Tribunal Supremo español.

4 Sin duda, esta caracterización se encuentra hoy como mayoritaria en la doctrina; el autor en cita la defiende en los siguientes términos: "para la averiguación de si hubo infracción de la norma de cuidado deberá preguntarse qué hubiera hecho el hombre diligente en la misma situación".

5 No se quiere decir nunca que las normas sociales sean las que regulan una sociedad con independencia de aquellas jurídicas; por el contrario, aunque en muchos casos son las normas sociales el origen de las jurídicas, son sólo estas últimas las que fundamentan el reproche penal subyacente (Cfr. Piña, 2005, p. 401). 
6 Aunque Engisch otorga cierta primacía a este elemento en tanto abstracción del proceso causal, es enfático en afirmar que no es el único elemento a valorar dentro del aspecto subjetivo del delito imprudente.

7 También la sociedad misma dicta ciertas normas con efectos jurídicos: la ley del arte (lex artis) de los médicos es un claro ejemplo de una norma emitida por un sector particular de la sociedad ajeno al aparato estatal.

8 Indirectamente, podría afirmarse que a los conductores también aplica toda vez que deben respetar tales normas peatonales mientras conducen, pero la verdad es que deben obedecer es la norma que regula la semaforización (el semáforo debería estar en rojo,) o la atinente al signo de pare (que obliga a detenerse ante ciertas cuadras), ambas propias de conductores. La prueba está en que si un peatón cruza prudentemente la calle y es arrollado por un carro debido a una falla en el semáforo, no será imputable un eventual resultado típico al conductor dado que no violó su deber objetivo de cuidado.

9 Debe tenerse muy en cuenta, que el grado exigible no supone nunca un promedio basado en figuras como el hombre medio o similares; por el contrario, él es siempre un mínimo, nunca un promedio. Supóngase el siguiente evento: la aspirante a secretaria A se presenta a una entrevista en la cual le exigen que tenga conocimientos de español e inglés. Ella le comenta al empleador que sabe hablar ambos idiomas a la perfección, pero que desconoce por completo el alemán. Éste le contesta que sólo requiere saber español e inglés, y que no le interesa el alemán. Ella, muy honesta, le replica que es usual para las secretarías que sepan tres idiomas. De ser contratada por cumplir con el requisito de idiomas (esto es: español y alemán), ¿haría parte de sus funciones escribir cartas en alemán? Es evidente que el estándar exigible está dado por el mínimo de los requisitos para cumplir con el rol y no por el promedio de aquellos que lo cumplen. De lo contrario, se llegaría al absurdo de que aun cuando fue contratada para cumplir unas funciones, sea despedida por no saber cumplir otras que no hacían parte del conjunto de exigencias previsto para el cargo. Ahora, claro está, esto no implica que de saber un español superior al promedio para las secretarias, A no deba emplearlo en su trabajo, pues dicho conocimiento sí hace parte del conjunto de exigencias que debe cumplir aquél que fuere elegido para desempeñar el cargo.

10 Incluso, si se quiere, es conveniente adicionar la voz exclusiva a la calidad de la fuente. Pues, no se trata de que el rol social incida de alguna forma vaga en la cadena que desembocó en la producción del conocimiento. Realmente, es necesario que dicho rol haya influido de forma determinante en la producción del conocimiento, de tal forma en que de no ser por aquél, éste jamás se hubiera dado. Reyes propone un contraejemplo basado en el encargado de limpiar vidrios de los carros que llega a llenar de gasolina un vehículo a una estación y que, 
en horas laborales, adquiere ciertos conocimientos de mecánica gracias al roce constante con dicho medio. Cabe destacar, sin embargo, que el rol social que desempeña el limpiavidrios no es más que una excusa para que éste haya obtenido el conocimiento que, dados los supuestos del ejemplo, es más bien circunstancial. En cuanto a la especialidad formal se refiere, ésta sólo se predica si el rol social no fue la causa determinante del conocimiento -como en el caso del mesero-, por lo tanto lo aquí expresado es de aplicación excepcional y sumamente restringida.

11 Cabe preguntarse si, teniendo en cuenta esto, un conocimiento que no repara al rol social es siquiera materialmente especial; la respuesta parece negativa pero, por cuestiones de metodología, sobra desarrollar a fondo este punto.

12 Como bien lo apunta el profesor Reyes, esto es lo mismo a afirmar que son materialmente especiales los conocimientos que no están incluidos dentro de los presupuestos de exigibilidad de una posición jurídica.

13 Desborda por completo los límites de este trabajo tratar cuestiones que, aunque son trascendentales para estos efectos, requieren de un estudio mucho más extenso que el aquí pretendido. Ahora bien, en relación con el problema atinente a si en el presente caso se está ante una acción o una omisión, parece viable afirmar que la figura de posición de garante es igualmente predicable de la acción y de la omisión (Ver. Jakobs, 1997, p. 175 y ss).

14 Recuérdese que, a diferencia del evento contrario, en los casos en los cuales media una posición de garante el sujeto debe hacer todo lo posible para evitar en el sentido estudiado con respecto a los deberes de cuidado individualizadores. Hablar de conocimientos especiales cuando media una posición de garante es un contrasentido, pues según la definición aquí esbozada para ser especiales materialmente esos conocimientos deben ser ajenos al conjunto de exigencias que el Estado impone al sujeto.

15 No es este el momento en el cual ha de determinarse si éste ha de responder o no. Únicamente se pretende introducir la diferencia entre los distintos tipos de conocimientos.

16 Recuérdese, igualmente, que para el conocimiento sobre una técnica novedosa en medicina sólo puede estimarse especial con respecto a aquel propio del estado del arte de la medicina (de la especialidad $\mathrm{x}$ ), jamás con respecto a lo que sabe el ciudadano promedio o incluso la enfermera, como ya se dijo más arriba.

17 Tal sería el caso en el que un médico cirujano conocedor de una técnica novedosa decide aplicarla para ahorrar tiempo en la cirugía y, a causa 
de una mala ejecución, el paciente sufre complicaciones que terminan por acabar con su vida.

18 En tal situación, si no hay manipulación alguna, el mesero no responde penalmente pues es un caso común de conocimientos especiales tal y como aquí se han definido. La única diferencia radica en que en tal escenario el mesero seguramente experimentaría cierta satisfacción con la muerte del comensal, lo que en ningún momento altera el carácter no delictivo de la conducta desplegada.

\section{Referencias}

Atienza, M. (1988). Introducción al Derecho. México: Fontamara.

Baumann, J. (1973). Derecho penal: conceptos fundamentales y sistema. $4^{\mathrm{a}}$ ed. (Trad. C. A. Finzi). Buenos Aires: Depalma.

Bustos, J. (1987). Control social y sistema penal. Barcelona: PPU.

Bustos, J. (2006). Lecciones de Derecho penal: parte general. Madrid: Trotta.

Cancio, M. (1994). Los orígenes de la teoría de la adecuación social: teoría final de la acción e imputación objetiva. Bogotá: Universidad Externado de Colombia.

Cancio, M. (2001). Lineas básicas de la teoría de la imputación objetiva. Mendoza: Ediciones Jurídicas Cuyo.

Cancio, M. (2005). Algunas reflexiones sobre lo objetivo y subjetivo en la teoría de la Imputación Objetiva. En M. Bolaños (comp.). Imputación Objetiva y dogmática penal. (pp. 205-228). Mérida: Universidad de los Andes.

Caro, J. A. (2006). Imputación subjetiva. En Revista Peruana de Doctrina y Jurisprudencia Penales $\mathrm{N}^{\circ} 7$ (pp. 235-252). Lima: Editorial Grijley.

Castañán, J. (1982). Derecho civil español, común y foral, I, (12 Ed). Madrid: Reus.

Cerezo, J. (2008). Derecho penal: parte general. Buenos Aires: B de F.

Choclán, J. (1998). Deber de cuidado y delito imprudente. Barcelona: Bosch.

Cobo, M. y Vives, T. (1999). Derecho penal: parte general. (5a ed.). Valencia: Tirant lo Blanch.

Corcoy, M. (2008). Delito Imprudente. (2a ed.) Buenos Aires: Editorial B de F.

Córdoba, F. (1996). Consideraciones en torno a la teoría de la imputación objetiva en el sistema de Claus Roxin. En Cuadernos de doctrina y jurisprudencia penal. Ad-Hoc. (1-2). 
Engisch, K. (2008). La causalidad como elemento de los tipos penales (Trad. M. A. Sancinetti). Buenos Aires: Hammurabi.

Exner, F. (1957). Biología criminal en sus rasgos fundamentales (Trad. J. del Rosal). Barcelona: Bosch.

Fakhouri, Y. (2012). El objeto del dolo en el derecho penal. Bogotá: Universidad Externado de Colombia.

Fiandaca, G y Musco, E. (2006). Derecho penal: parte general. Trad. Pablo Eiora. Bogotá: Temis.

Frisch, W. (2004). Comportamiento típico e imputación del resultado. (Trad. J. Cuello Contreras y J. L. Serrano González de Murillo). Madrid: Marcial Pons.

Frisch, W. (2006). Desvalor e imputar: sobre la imputación objetiva en el Derecho penal. (2a ed.) Trad. R. Robles Planas. Montevideo: Editorial B de F.

García, P. (2004). La imputación subjetiva en Derecho penal. En Revista Peruana de Doctrina y Jurisprudencia penales, No. 5 (pp. 157 y ss.). Lima: editorial Grijley.

Gimbernat, E. (2007). Delitos cualificados por el resultado y causalidad. $2^{\mathrm{a}}$ ed. Buenos Aires: Ed. B de F.

Grosso, M. (2006). Dos estudios sobre la nueva teoría del delito. Bogotá: Ibáñez.

Hirsch, H. J. (1993). La polémica en torno a la acción y de la teoría del injusto en la ciencia penal alemana. (Trad. C. J. Suárez González). Bogotá: Universidad Externado de Colombia.

Hirsch, H. J. (1998). Acerca de la teoría de la imputación objetiva. En Nueva doctrina penal, 1998-A (pp. 87-110). Buenos Aires: Editores del Puerto.

Huerta, S. (1984). Sobre el contenido de la antijuridicidad. Madrid: Tecnos.

Jakobs, G. (1997). Derecho penal: Parte general: fundamentos y teoría de la imputación (Trad. Joaquín Cuello Contreras et al.). Madrid: Marcial Pons.

Jakobs, G. (1997b). Estudios de Derecho penal. (Trad. E. Peñaranda, C. Suárez y M. Cancio). Madrid: Civitas.

Jakobs, G. (1998). Imputación objetiva en el derecho penal (Trad. M. Cancio Meliá). Bogotá: Universidad Externado.

Jakobs, G. (2001). Injerencia y dominio del hecho: dos estudios sobre la parte general del derecho penal (Trad. M. Cancio Meliá). Bogotá: Universidad Externado de Colombia. 
Jakobs, G. (2004). Indiferencia como dolo indirecto (trad. C. Pérez del Valle). En J. López-Barja de Quiroga y J. M. Zugaldía Espinar. Dogmática y Ley Penal: libro homenaje a Enrique Bacigalupo. T. I. (pp. 345-358) MadridBarcelona: Marcial Pons.

Jakobs, G. (2011). ¿Imputación subjetiva sin imputación objetiva? (Trad. F. Córdoba). En Maier, J. B. J. et al. Dogmática penal entre naturalismo y normativismo: Libro homenaje a Eberhard Struensee. Buenos Aires: AdHoc.

Jescheck, H. H. (1981). Tratado de Derecho penal. Parte General. T. I. (Trad. S. Mir Puig y F. Muñoz Conde). Barcelona: Editorial Bosch.

Jescheck, H. H. (1993) Tratado de Derecho Penal. 4. Ed. (Trad. J. L. Manzanares Samaniego). Granada: Comares.

Kant, I. (2006). Crítica de la razón pura. Trad. Pedro Ribas. México: Taurus.

Kaufmann, A. (2006). Dogmática de los delitos de omisión. (Trad. J. Cuello Contreras y J. L. Serrano González de Murillo). Barcelona: Marcial Pons.

Kaufmann, A. (1976). El delito culposo (Trad. Moisés Moreno Hernández). En Revista Nuevo pensamiento penal, No. 5 (pp. 467-486). Buenos Aires: Depalma.

Larenz, K. (1966). Metodología de la ciencia del Derecho. (Trad. Enrique Gimbernat Ordeig). Barcelona: Ariel.

López, D. (2008). El problema de la subjetividad en la explicación sociológica: una mirada a partir del debate Schutz-Parsons. En Revista de Estudios Sociales, No. 31 (pp. 72-83) Bogotá: Universidad de los Andes.

López, C. (2005). La teoría de la Imputación Objetiva. En M. Bolaños (comp.). Imputación Objetiva y dogmática penal. (pp. 123-171). Mérida: Universidad de los Andes.

Luhmann, N. (1983). Sistema jurídico y Dogmática jurídica. (Trad. Ignacio Otto Pardo). Madrid: centro de estudios constitucionales.

Luhmann, N. (1998). Sistemas sociales: lineamientos para una teoría general. Trad. Silvia Pappe et al. Barcelona: Anthropos.

Martínez, M. (1992). La imputación objetiva del resultado. Madrid: Edersa.

Maurach, R. (1962). Tratado de Derecho penal, t. I. (Trad. J. Córdoba Roda). Barcelona: Ariel.

Mezger, E. (2010). Tratado de Derecho penal. V. I. (Trad. José Arturo Rodríguez Muñoz). Buenos Aires: Hammurabi. 
Mir, S. (1982). Función de la pena y Teoría del Delito en el Estado social y democrático de Derecho. (2a ed.)

Mir, S. (2003). Significado y alcance de la imputación objetiva en el Derecho penal. Revista Electrónica de Ciencia Penal y Criminología. (05). Recuperado de http:/ / criminet.ugr.es/recpc.

Mir, S. (2011). Derecho penal. Parte General. (9 ed). Montevideo: B de F.

Montealegre, E. (1988). La culpa en la actividad médica: imputación objetiva y deber de cuidado. Bogotá: Universidad Externado de Colombia.

Muñoz, F. (2010) Derecho penal: parte general. 8a ed. Valencia: Tirant lo Blanch.

Nino, C. (1997). Introducción al análisis del Derecho. Barcelona: Ariel.

Paredes, J. M. (1995). El riesgo permitido en derecho penal (Régimen jurídico penal de las actividades peligrosas). Madrid: Ministerio de justicia e interior.

Parsons, T. (1966). El sistema social. Trad. José Jiménez Blanco y José Cazorla Pérez. Madrid: Ediciones de la Revista de Occidente.

Piña, R. G. (2002). El tipo subjetivo en el delito imprudente. En Revista de Derecho penal, Delitos culposos. No. 1, enero-junio (pp. 55-76). Buenos Aires: Ed. Rubinzal Culzoni.

Piña, J. I. (2005). Rol social y sistema de imputación: una aproximación sociológica a la función del Derecho penal. Barcelona: Bosch.

Posada, R. (coord.) (2008). El dolo en el Código penal del 2000. En R. Posada (Coord.). Temas de Derecho penal (pp. 1-74). Bogotá: Temis.

Quine, W. V. O. (1980). Two Dogmas of Empirism, en From a Logical Point of View: 9 Logico-philosophical essays. Cambridge, Mass.: Harvard University Press.

Quintero, G. (1989). Derecho penal. Parte General. Teoría Jurídica el Delito. (2a ed.). Madrid: Marcial Pons.

Radbruch, G. (1955). Historia de la criminalidad: ensayo de una criminología histórica (Trad. Enrique Gwinner). Barcelona: Bosch.

Recasens, L. (1986). Tratado general de filosofía del Derecho. México: Porrúa.

Reyes, Y. (1992). Fundamentos teóricos de la imputación objetiva. En $A D P C P$, T. XLV, Fasc. III, Recuperado de http://portal.uclm.es/ descargas/idp_docs/doctrinas/reyes\%20alvarado.pdf.

Reyes, Y. (2002). El concepto de imputación objetiva. En Revista Derecho penal contemporáneo, No. 1 (pp. 5-34). Bogotá: Legis. 
Reyes, Y. (2005). Imputación objetiva. ( $3^{\mathrm{a}}$ ed.) Bogotá: Temis.

Reyes, Y. (2005a). Ubicación del dolo y la imprudencia en una concepción normativa de la teoría del delito, en Dogmática y criminología. Dos visiones complementarias del fenómeno delictivo ((pp. 515-540). En Libro homenaje a Alfonso Reyes Echandía. Bogotá: Legis.

Reyes, Y. (2005b). El concepto de imputación objetiva. En M. Bolaños (comp.). Imputación Objetiva y dogmática penal (pp. 173-204). Mérida: Universidad de los Andes.

Reyes, Y. (2006). Causalidad y explicación del resultado. En Revista Derecho penal contemporáneo, No. 14 (pp. 5-38). Bogotá: Legis.

Rodríguez, G. (1978). Derecho penal: parte general. I,

Roxin, C. (1976). Problemas básicos del derecho penal. (Trad. De Diego Manuel Luzón Peña). Madrid: Reus.

Roxin, C. (1997). Derecho penal: parte general. T. I (Trad. Diego Manuel Luzón Peña, et al.). Madrid: Civitas.

Rúa, G. S. (1999) Los conocimientos especiales del autor dentro del marco de la imputación objetiva, en Cuadernos de Doctrina y Jurisprudencia Penal, t. 9-A, (pp. 603). Buenos Aires: Ad-hoc.

Ruiz, C. E. (2011). La graduación del delito imprudente. Bogotá: Universidad Externado de Colombia.

Sacher, M. (1998). Evolución del tipo subjetivo. Bogotá: Universidad Externado de Colombia.

Sancinetti, M. (1998). Observaciones sobre la teoría de la imputación objetiva. En Sancinetti, M. et al. Estudios sobre la teoría de la imputación objetiva (pp. 37-74) Buenos Aires: Ad-Hoc.

Schünemann, B. (1998). Consideraciones sobre la imputación objetiva (trad. Mariana Sacher de Köster). En Teorías actuales en el Derecho Penal. $75^{\circ}$ Aniversario del Código Penal. (pp. 219-248) Buenos Aires: Ad-Hoc.

Sentencia (2007, noviembre 8), rad. 27388. M.P. Julio Enrique Socha Salamanca. Corte Suprema de Justicia. Sala de Casación Penal.

Serrano-González de Murillo, J. L. (2011). Sobre la consideración de los "conocimientos especiales" del sujeto en el juicio objetivo de peligro. En Maier, J. et al. Dogmática penal entre naturalismo y normativismo: Libro homenaje a Eberhard Struensee. Buenos Aires: Ad-Hoc.

Serrano, J. L. (1991). Teoría del delito imprudente: doctrina general y regulación legal. Madrid: Ministerio de Justicia. 
Silva, J. M. (1986). El delito de omisión. Concepto y sistema. Barcelona: Bosch.

Silva, J. M. (1992). Aproximaciones al derecho penal contemporáneo. Barcelona: Bosch.

Silva, J. M. (2009). Tiempos de Derecho penal: escritos breves sobre teoría y práctica, vida social y economía. Madrid: Edisofer.

Silva, J. M. (2011). La expansión del Derecho penal: aspectos de la política criminal en las sociedades postindustriales. Madrid: Edisofer.

Stratenwerth, G. (1976). Derecho penal. Parte General I. (trad. G. Romero) Madrid: Edersa.

Stratenwerth, G. (2000). Strafrecht Allgemeiner Teil I (4. Ed.). Köln: Carl Heymanns Verlag.

Struensee, E. (1995). Acerca de la legitimación de la "imputación objetiva" como categoría complementaria del tipo objetivo (Trad. F. Guariglia). En J. B. Maier y A.M. Binder: El Derecho penal hoy. Homenaje al profesor David Baigún (pp. 251-272). Buenos Aires: Editores del Puerto.

Torío, A. (1974). El deber objetivo de cuidado en los delitos culposos. En ADPCP, T. XXVII, Fasc. I. (enero-abril, 1974), pp. 25-59.

Velásquez, F. (2009) Derecho penal, Parte general. (4 ed.). Medellín: Comlibros.

Wessels, J. (1980). Derecho penal: parte general. 6a. Ed. (Trad. Conrado A. Finzi). Buenos Aires: Depalma.

Welzel, H. (1993). Derecho penal alemán. (Trad. J. Bustos Ramírez y S. Yánez Pérez). Santiago de Chile: Editorial Jurídica de Chile.

Wolter, J. (2004) et al. El sistema integral del derecho penal: delito, determinación de la pena y proceso penal. Madrid: Marcial Pons.

Wright, G. (1997). Normas, verdad y lógica (Trad. C. Alarcón Cabrera). México D. F.: Fontamara. 